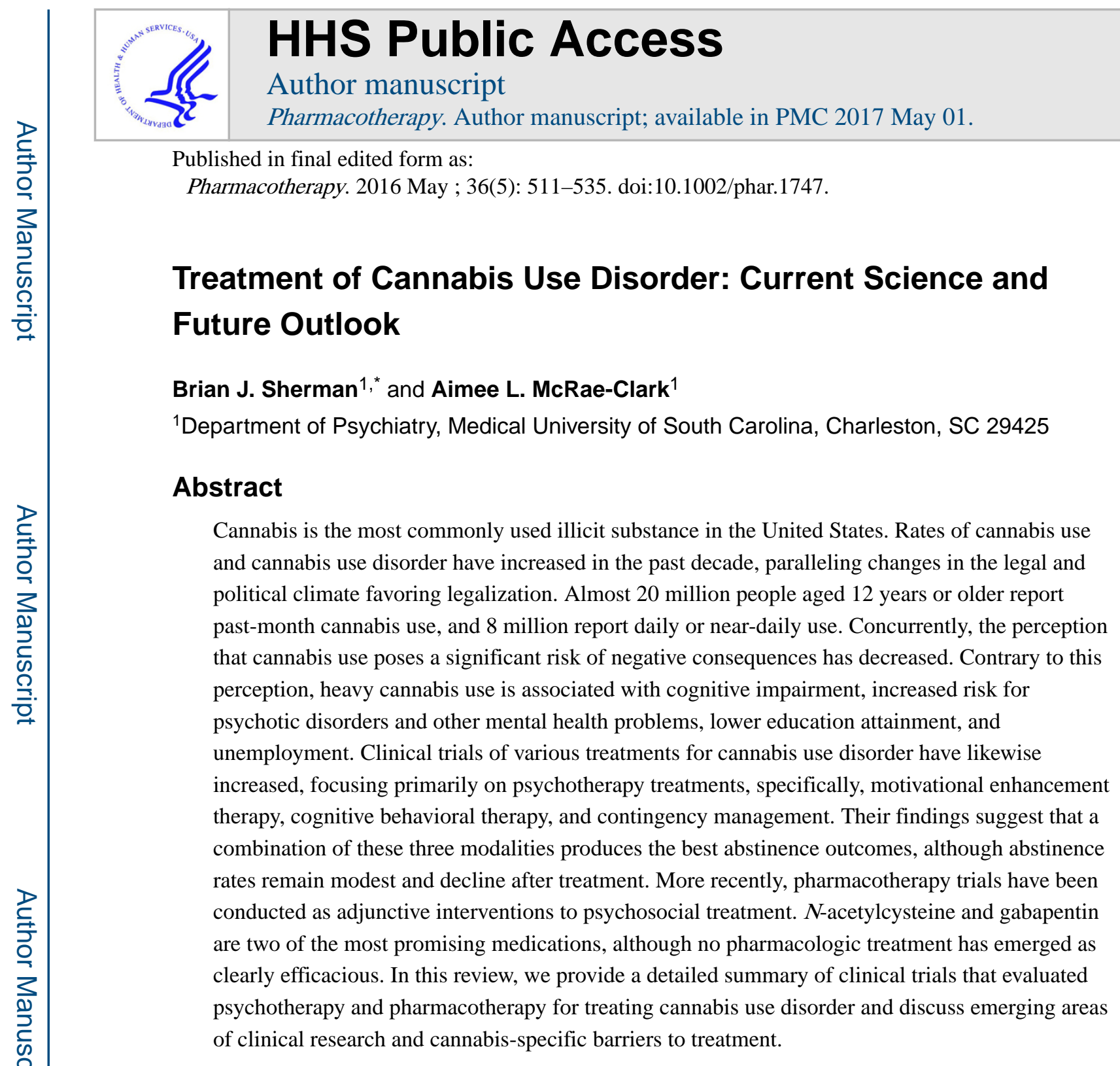

\title{
Keywords
}

cannabis; marijuana; treatment; cannabis use disorder; psychotherapy; pharmacotherapy; intervention; review

Cannabis is the most commonly used illicit drug in the United States, with an estimated 19.8 million people aged 12 years or older (7.5\% of the population) reporting past-month use. ${ }^{1}$ Daily or near-daily use has increased from 5.1 million people between 2005 and 2007 to 8.1 million people in $2013 .{ }^{1}$ Meanwhile, rates of cannabis dependence are as high as $42 \%$ among heavy users ${ }^{2}$ and $9 \%$ among all users. ${ }^{3}$ Heavy cannabis use is associated with significant negative consequences including increased risk of psychotic disorders ${ }^{4}$ cognitive impairment, ${ }^{5}$ higher unemployment, ${ }^{6}$ lower educational attainment and life satisfaction, ${ }^{6}$ and poor mental health outcomes. ${ }^{7}$ Cannabis use disorder (CUD) is characterized by a continued problematic pattern of use despite negative consequences, which causes

\footnotetext{
*Address for correspondence: Brian J. Sherman, 125 Doughty Street, Suite 190, Charleston, SC 29425; ; Email: shermanb@ musc.edu
} 
significant distress or impairment in functioning. For full Diagnostic and Statistical Manual of Mental Disorders - Fifth Edition (DSM-5) ${ }^{8}$ criteria see Table 1. Despite such high rates of cannabis use and associated consequences, only 845,000 individuals received treatment for CUD in $2013,{ }^{1}$ leaving the vast majority of those with CUD untreated.

Concurrently, there has been a dramatic shift in the legal, political, and cultural climates surrounding cannabis over the last decade. Overall, 27 states plus the District of Columbia have legalized cannabis in some form, and 53\% of the general public now believes that cannabis should be legal compared to $32 \%$ in $2006 .{ }^{9}$ Among $12-17$-year-old individuals, the perception that smoking marijuana 1 or 2 times per week poses a "great risk" has decreased from $54.6 \%$ in 2007 to $39.5 \%$ in $2013 .{ }^{1}$ Given these facts, it is likely that the number of individuals with CUD will increase in the coming years as cannabis becomes even more widely accepted and the perceived risk continues to decline.

Effective treatments for CUD are clearly in need. Psychotherapeutic treatments are the most widely studied and have demonstrated effectiveness in reducing frequency and quantity of use, but abstinence rates remain modest and decline after treatment. ${ }^{10-12}$ In addition, although pharmacologic treatments have shown promise, none have emerged as clearly efficacious. In this article, we review the extant literature on the treatment of cannabis use disorder and discuss promising new avenues of research.

\section{Psychotherapeutic Treatments}

Psychotherapeutic treatments for CUD have evolved significantly since the first clinical trials in the mid-1990s. To date, clinical trials have primarily focused on cognitivebehavioral therapy (CBT), motivational enhancement therapy (MET), and contingency management $(\mathrm{CM})$, and the evidence base suggests that a combination of the three treatment modalities produces the best outcomes. ${ }^{10,13-15}$ A summary of clinical trials evaluating psychotherapy for treatment of CUD is provided in Table 2.

\section{Cognitive-Behavioral Therapy}

Cognitive-behavioral therapy helps patients identify contingencies of using behavior, develop relapse prevention and coping skills, and pursue alternative prosocial behaviors. Techniques include self-monitoring, cognitive restructuring, cost-benefit analysis, role playing, and modeling. Through homework completion and successful use of coping skills, self-efficacy is enhanced, and patients are more likely to effectively employ skills again in the future.

Stephens, Roffman, and Simpson conducted the first formalized cognitive-behavioral approach for CUD. ${ }^{16}$ The authors operationalized concepts from Marlatt and Gordon's Relapse Prevention Model ${ }^{17}$ and randomly assigned 212 treatment-seeking marijuana users into either the relapse prevention group or social support group. All participants evidenced significant reductions in frequency of marijuana use and marijuana-related problems; however, no significant between-group differences emerged. In addition, where almost two thirds of all participants achieved initial posttreatment abstinence, only $14 \%$ maintained abstinence at one-year follow-up. 
Stephens, Roffman, and Curtin conducted a subsequent study examining extended versus brief interventions and included a delayed treatment control group for comparison. ${ }^{18}$ Two hundred ninety-one adult treatment-seeking marijuana users were randomly assigned to a 14-session relapse prevention support group (RPSG), a 2-session individual assessment and intervention (IAI), or a delayed treatment control (DTC). Again, no significant differences between active treatment conditions (RPSG and IAI) were observed; however, participants in both the RPSG and IAI showed greater reductions in days used, sessions per day, depression, and marijuana-related problems compared to DTC participants.

To further examine optimal treatment duration, Copeland, Swift, Roffman, and Stephens ${ }^{19}$ compared CBT interventions of varying lengths in a randomized controlled trial of 229 treatment-seeking adult marijuana users. Participants were assigned to either a 6-session CBT treatment (6CBT), a 1-session CBT treatment (1CBT), or a delayed treatment control (DTC). All treatment and follow-up assessments were individual and in-person with followup occurring at 24 weeks from baseline. Both 1CBT and 6CBT reported higher abstinence rates at follow-up compared to DTC. Dependence severity scores did vary across groups and were highest among the DTC group, followed by 1CBT, and then 6CBT. Overall, both 6CBT and 1CBT did better than DTC on marijuana use outcomes, and only on dependence severity did 6CBT and 1CBT differ significantly. Results suggest limited benefit of longer treatment duration as both active treatments did better than the control group on primary outcomes; however, results of subsequent studies, such as the Marijuana Treatment Project ${ }^{12}$ (discussed below) support the benefit of more extended interventions.

\section{Motivational Enhancement Therapy}

Motivational enhancement therapy (MET) is based on motivational interviewing (MI) principles ${ }^{20}$ and seeks to enhance motivation to change by providing nonjudgmental feedback, exploring and resolving ambivalence, and collaborative goal setting. The therapist uses an empathic nonconfrontational approach to elicit "change talk" (e.g., "I really need to stop smoking pot before I get into trouble again"), which predicts subsequent behavior change.

The Marijuana Check-Up (MCU) $)^{21,22}$ is a brief motivational intervention modeled after the Drinker's Check-up, ${ }^{23-25}$ which has shown effectiveness in reducing alcohol consumption among non-treatment-seeking, alcohol-dependent individuals. The MCU was designed as a one-session motivational intervention and demonstrated utility in engaging ambivalent marijuana users in treatment. ${ }^{22} \mathrm{~A}$ subsequent efficacy trial ${ }^{21}$ added a personalized motivational feedback session and found reductions in days of use, sessions per day, and dependence symptoms among those receiving personalized feedback compared to multimedia feedback and delayed feedback control conditions.

Martin and Copeland developed the Adolescent Cannabis Check-Up (ACCU), a brief 2session motivational intervention modeled after the MCU. ${ }^{26}$ In a randomized controlled, trial the authors compared the ACCU to a delayed treatment control group (DTC) among 40 non-treatment-seeking adolescents. Compared to the DTC, the 2-session MET intervention (ACCU) demonstrated efficacy in reducing days of use, number of dependence symptoms, and quantity used per week from baseline to 3-month follow-up. A larger replication study 
conducted by de Gee and colleagues in the Netherlands did not find a significant treatment effect of ACCU over time. ${ }^{27}$ However, baseline level of use appeared to moderate the effect of treatment on marijuana use; heavy users (who smoked more than 14 joints per week) receiving the MET intervention showed greater reduction in quantity of use compared to heavy users in the control condition. Of note, the original ACCU participants were heavier users than the Dutch sample, which, combined with the moderation effect reported by de Gee and colleagues, suggests that brief MET interventions may be more effective with heavier users. Further, the investigators included an information session as the control condition, rather than a delayed treatment control, which may have impacted their findings.

A randomized controlled trial by McCambridge, Slym, and Strang compared a singlesession MI intervention (MI) to a drug information and advice control intervention (DIA). ${ }^{28}$ The sample of 326 adolescents was recruited from schools across Great Britain, and they were randomly assigned to either MI or DIA. Frequency of cannabis use, cannabis-related problems, and dependence severity were all reduced from baseline to 6-month follow-up, but there was no treatment condition effect. However, the study was confounded by low fidelity to MI and practitioner effects. McCambridge and colleagues conducted a secondary analysis and found that after controlling for practitioner effects, MI spirit and proportion of complex reflections independently predicted abstinence at 3-month follow-up. ${ }^{29}$ No other aspects of MI predicted cannabis cessation.

Brief motivational interventions have also been studied among specific populations such as young adult women. Women tend to initiate substance use earlier than $\operatorname{men}^{30}$ and escalate their use more quickly; they may therefore be at elevated risk for psychosocial consequences of substance abuse. ${ }^{31,32}$ To examine the efficacy of a brief MI intervention among nontreatment-seeking women aged 18-24 years, Stein and colleagues randomized 332 participants into a 2-session MI intervention or an assessment only control (AO). ${ }^{33}$ At the 3month follow-up, MI participants showed a significant reduction in days of use compared to AO. Desire to quit at baseline moderated this treatment effect over time such that participants who expressed any desire to quit at baseline evidenced a reduction in expected probability of use at 1 month, 3 months, and 6 months compared to those who expressed no desire to quit.

\section{MET/CBT}

Many studies have sought to capitalize on the unique strengths of CBT and MET by studying a hybrid treatment approach. The largest treatment study to date for adult cannabis users was the Marijuana Treatment Project (MTP). ${ }^{12}$ MTP was a multisite, randomized clinical trial that sought to clarify the optimal duration, frequency, and intensity of behavioral treatments for CUD. Across three geographically and demographically diverse treatment sites, 450 cannabis-dependent adults were randomized into a 2-session motivational enhancement therapy intervention (MET), a 9-session MET plus cognitivebehavioral and case management intervention (CBT/MET/case), or a delayed treatment control (DTC). Assessments were conducted at baseline, 4, 9, and 15months after randomization. At 4 months, the 9 -session and 2-session participants showed greater reductions in percentage of use days compared to DTC, and abstinence rates were 
significantly higher in the 9-session treatment group compared with the 2-session and DTC groups, which did not significantly differ from each other. At 9- and 15-month follow-up, the 9-session intervention showed greater reductions in days of use, dependence symptoms, and abuse symptoms compared to the 2-session intervention, and reductions in days of use was maintained at 15-month follow-up, although the effect was small. Overall, results suggest that the 9-session combined MET/CBT/case approach was most effective and that longer treatment duration may result in better outcomes.

The Cannabis Youth Treatment study is another large clinical trial (600 participants) that examined the efficacy and cost-effectiveness of five short-term psychotherapy treatments for adolescents with CUD across four study sites and two related clinical trials. ${ }^{34}$ Trial 1 compared a 5-session MET/CBT treatment (MET/CBT5), a 12-session MET/CBT treatment (MET/CBT12), and a family support network intervention (FSN). MET/CBT5 consisted of two individual MET sessions plus three group CBT sessions. The MET/CBT12 intervention was identical to MET/CBT5 but added an additional seven group CBT sessions. FSN extended MET/CBT12 further adding six parent group sessions, four home visits, and case management. Trial 2 compared the same MET/CBT5 with the adolescent community reinforcement approach (ACRA), and multidimensional family therapy (MDFT). ACRA involved of 10 individual sessions and four sessions with the caregivers to educate them on how to support the adolescent's abstinence. MDFT included 12-15 sessions (6 with the adolescent alone, 3 with the parents alone, and 6 with the whole family) and involved therapeutic processes of setting the stage, working the themes, and sealing the changes.

Adolescents and their families were randomly assigned to one of the five conditions, and outcomes included days of abstinence from randomization to 12-month follow-up and being in recovery at the end of the study (defined as living in the community with no reported use, abuse, or dependence symptoms in the last month). All groups improved in days of abstinence and percentage in recovery, but there were no significant between-group effects. Cost-effectiveness did vary significantly by intervention, with MET/CBT5 being most costeffective in trial 1 and ACRA the most cost-effective in trial 2. Two major limitations of the study included not having a control group and not using confirmatory urine drug screenings, relying entirely on self-report for assessment of cannabis use.

Toward enhancing long-term outcomes, a recent study examined whether adding posttreatment MET check-ups would augment standard MET/CBT treatment. ${ }^{35}$ The authors randomized 74 participants into either MET/CBT with maintenance check-ups (MCU) or MET/CBT with no check-ups (NCU). The MCU group received two posttreatment checkups at 1 month and 3 months after treatment. Both MET/CBT groups received standard 9session treatment modeled after the MTP manual, and both groups were offered additional sessions, but the NCU group had to initiate on their own whereas the MCU group was encouraged, when appropriate, during scheduled check-ups. Marijuana use outcomes were assessed immediately after treatment and again 6 months later; the two MCU checkups occurred between these assessments. Abstinence rates were higher for the MCU group compared to the NCU group immediately after treatment and 6 months after treatment. MCU participants also evidenced a reduction in days of use immediately after treatment compared to NCU participants, but not 6 months later. Lastly, MCU participants did not re- 
engage with treatment more often than NCU participants, counter to the hypothesis. Although the MCU group appeared to respond better to treatment, there was no evidence that the additional check-ups were instrumental in these results since changes occurred prior to the check-up sessions. As the authors suggested, the promise of additional sessions itself may have enhanced self-efficacy and provided encouragement, resulting in better outcomes among MCU participants.

\section{MET/CBT plus Contingency Management}

$\mathrm{CM}$ has been studied widely in substance abuse treatment, often as an adjunct to psychotherapy. CM is based on operant conditioning of a target behavior (e.g., negative urine drug screen, session attendance) and is most effective when reinforcement opportunities are frequent, reinforcers immediately follow target behavior, perceived value of the reinforcer is high (although the actual value may be low), the reinforcement schedule is escalating (i.e., opportunities for reinforcement increase with successive achievement of target behavior), and failure to meet the reinforcement criterion results in resetting of the reinforcement schedule.

Budney, Higgins, Radonovich, and Novy first examined CM as an adjunct to behavioral treatment for CUD among 60 cannabis-dependent, treatment-seeking university students. ${ }^{13}$ Participants were randomly assigned to one of three interventions: motivational enhancement therapy (MET), motivational enhancement therapy plus behavioral skills training (MBT), or MBT plus an abstinence-based voucher program (MBTV). An escalating reinforcement schedule was used for consecutive negative urine drug screens (UDSs), and a bonus was earned for every two consecutive negative UDSs. Overall, marijuana use and consequences of use decreased across groups. However, the MBTV group evidenced significantly longer periods of abstinence during treatment (4.8 weeks) than both the MBT (2.3 weeks) and M (1.6 weeks) groups, but no significant differences were noted between the MBT and M groups. In addition, at the end of treatment, a greater percentage of MBTV participants were abstinent (35\%) compared to MBT (10\%) or M (5\%) participants. The addition of an abstinence-based voucher program to MBT promoted longer periods of abstinence during treatment and greater point prevalence abstinence at the end of treatment.

A follow-up study by Budney and colleagues examined the longer-term effects of an abstinence-based voucher program and tested whether CBT enhanced the effect. ${ }^{10}$ Assessments of substance use and related problems were conducted at baseline, end of treatment, and every 3 months through 1 year after treatment. Ninety participants were randomly assigned to CBT only (CBT), abstinence-based voucher program only (V), or CBT plus vouchers (CBT-V). CBT and CBT-V interventions included 14 weekly sessions focused on enhancing motivation and building coping and relapse prevention skills, whereas the voucher conditions were reinforced for negative UDS using the same procedures from Budney et al. ${ }^{13}$ CBT-V achieved greater posttreatment abstinence levels compared to CBT alone, whereas CBT-V and V did not significantly differ. There was a main effect of treatment condition on longest period of continuous abstinence during treatment; participants in the $\mathrm{V}$ condition achieved significantly longer periods than CBT participants, and there was no significant difference between $\mathrm{V}$ and CBT-V. Taken together, findings 
suggested that vouchers alone predict abstinence during treatment and that CBT provides durability of this effect over time. A randomized clinical trial comparing MET/CBT, MET/CBT/CM, CM only, and case management control among 240 marijuana-dependent individuals resulted in similar patterns. ${ }^{11}$ The $\mathrm{CM}$ only condition had the highest abstinence rates at the end of treatment, and MET/CBT/CM condition showed the greatest durability of effects over time.

Augmentation with $\mathrm{CM}$ has been studied in unique at-risk populations as well. In a randomized clinical trial of 136 individuals referred by the criminal justice system for treatment of marijuana dependence, Carroll and colleagues examined the effects of drug counseling (DC) and CM when added to an MET/CBT intervention. ${ }^{36}$ The study compared four treatment conditions: MET/CBT alone, MET/CBT plus CM, DC alone, or DC plus CM. Each treatment was conducted over an 8-week study period. Two-track CM procedures allowed participants to earn vouchers for session attendance and negative urine drug screens (UDS). CM showed a main effect on attendance and negative UDS, and the combination of MET/CBT plus CM was most effective in targeting these behaviors compared to other treatments. A significant time by treatment interaction found that the MET/CBT only group continued to demonstrate reductions in marijuana use at 6 months compared to the other three groups. This study demonstrated the specificity of CM on target behaviors and greater durability of MET/CBT approaches.

CM has also been modified to examine mechanisms of change. Carroll and colleagues evaluated reciprocal enhancement by combining the strengths of the CM and CBT approaches to offset their relative weaknesses. ${ }^{14}$ Treatment-seeking, cannabis-dependent individuals $(\mathrm{N}=127)$, largely compelled by the criminal justice system, were randomly assigned to one of four conditions: $\mathrm{CM}$ for abstinence $\left(\mathrm{CM}_{\mathrm{abst}}\right), \mathrm{CM}$ for abstinence plus $\mathrm{CBT}\left(\mathrm{CM}_{\mathrm{abst}}+\mathrm{CBT}\right), \mathrm{CBT}$ alone $(\mathrm{CBT})$, or $\mathrm{CBT}+\mathrm{CM}$ for adherence $\left(\mathrm{CBT}+\mathrm{CM}_{\mathrm{adher}}\right)$. It was hypothesized that adding $\mathrm{CBT}$ to $\mathrm{CM}_{\mathrm{abst}}$ would enhance the effect by providing a generalizable and durable skill set to combat the rebound effect often found when the target behavior of CM (negative UDS) is no longer being reinforced. Adding CM for treatment adherence to CBT was hypothesized to enhance CBT by increasing attendance and homework completion in two areas where CBT often suffers. However, neither treatment appeared to enhance the other as predicted. CBT outcomes were not improved by adding $\mathrm{CM}_{\text {adher }}$, and adding $\mathrm{CBT}$ to $\mathrm{CM}_{\mathrm{abst}}$ actually worsened outcomes. Overall, $\mathrm{CM}_{\mathrm{abst}}$ alone predicted the most consecutive negative urine specimens and lowest percentage of positive urine specimens. Attrition was highest for the CBT alone group. Findings suggest that enhanced treatments may not be particularly well suited to this population, and additional studies are needed with diverse samples.

Enhanced self-efficacy has also been studied as a mechanism of change among cannabis dependent individuals. Litt, Kadden, and Petry examined a behavioral treatment designed to enhance coping self-efficacy by comparing the addition of two different CM interventions to standard MET/CBT in a randomized clinical trial. ${ }^{15}$ Participants received either MET/CBT $+\mathrm{CM}$ for homework completion, $\mathrm{MET} / \mathrm{CBT}+\mathrm{CM}$ for abstinence, or case management control. The authors hypothesized that reinforcing homework completion would increase self-efficacy, which would in turn lead to increased use of coping skills (and further 
enhanced self-efficacy), ultimately increasing sustained abstinence. Two hundred fifteen cannabis-dependent adults were randomized to the three interventions; MET/CBT interventions were based on the Marijuana Treatment Project ${ }^{12}$ manual. The MET/CBT/ $\mathrm{CM}_{\text {abst }}$ group achieved a longer period of initial abstinence than the $\mathrm{MET} / \mathrm{CBT} / \mathrm{CM}_{\mathrm{hmwk}}$ homework group (27.9 days vs. 18.6 days), but there were no other main effects of treatment on primary marijuana outcomes. Latent growth curve modeling, however, identified four treatment response trajectories: treatment nonresponders (43\%), late responders (25\%), early relapsers (12\%), and long-term abstainers (19\%). Continuous abstinence during treatment predicted membership in all "response" groups and enhanced self-efficacy predicted membership in the long-term abstainer group only. Long-term abstainers were also more

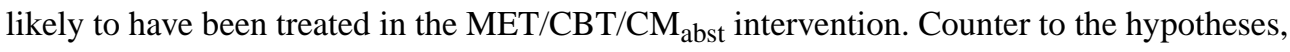
findings suggest that reinforcing abstinence may have enhanced self-efficacy more than reinforcing homework, and treatments that work to enhance self-efficacy while promoting continuous periods of abstinence may have better long-term effects on marijuana use outcomes.

\section{Alternate Approaches}

Although the majority of clinical trials for CUD have examined CBT, MET, and CM, alternate approaches have also been studied. Multidimensional family therapy (MDFT) is a family-based treatment that has shown promising results, particularly with adolescents. MDFT involves at least one caregiver and focuses on four interdependent treatment domains: the adolescent domain, the parent domain, the interactional domain, and the extrafamilial domain. Liddle and colleagues conducted a randomized trial comparing MDFT with CBT and assigned 224 substance-abusing adolescents (and their parents in the case of MDFT) to receive individual CBT or MDFT. ${ }^{37}$ Both interventions reduced adolescent cannabis consumption, but there were no significant between-group differences. MDFT participants evidenced greater reduction in problem severity, which was sustained through 12-month follow-up. A separate study comparing MDFT to CBT among adolescents with CUD found no treatment effects, although both groups did show significant reductions in frequency and quantity of cannabis use from baseline to one-year follow-up. ${ }^{38}$ MDFT participants also engaged in significantly more sessions and overall hours of therapy than CBT participants. Post-hoc analysis revealed a moderation effect of use severity on the relationship between treatment and days of use. High-severity users receiving MDFT reported 9.8 fewer days of use than high-severity users receiving CBT.

In light of growing evidence demonstrating health benefits of mindfulness meditation, one study sought to augment a traditional motivational intervention for cannabis-using women aged 18-29 years by adding a mindfulness component. ${ }^{39}$ This pilot study randomly assigned 34 women to either motivational interviewing plus mindfulness meditation (MM-MI [ $\mathrm{n}=$ $22])$ or an assessment only ( $\mathrm{AO})$ control group $(\mathrm{n}=12)$. A significant treatment effect indicated that women in the MM-MI condition used on fewer days at 1-month, 2-month, and 3-month follow-up compared to those in the AO condition. 


\section{Summary}

Psychotherapeutic treatments for cannabis use disorders have shown positive, although tempered, results. According to the literature, a combination of MET/CBT/CM $\mathrm{Cbst}_{\mathrm{abs}}$ produces the best outcomes reliably reducing frequency and quantity of use, with limited effects on sustained abstinence. Each approach appears to add something unique. MET is effective for engaging ambivalent individuals, abstinence-based CM leads to longer periods of continuous abstinence during treatment, and CBT works to enhance abstinence durability following treatment. The belief that one can resist using (i.e., self-efficacy) and longer periods of intreatment abstinence appear to be instrumental in predicting better long-term outcomes. Regarding treatment duration, there is evidence to suggest that longer duration improves outcomes, although the effect is small and the optimal range is unclear. There remains considerable room for improvement in the treatment of CUD, and future psychotherapy trials should continue to examine mechanisms of therapeutic change as well as alternative approaches.

\section{Pharmacologic Treatments}

Given the less-than-optimal results of psychosocial therapies, development of new treatment approaches for CUD is currently of significant interest. As such, pharmacologic interventions are being actively studied. Potential targets for medications to treat CUD include cannabis withdrawal symptoms, abstinence initiation or relapse prevention, and comorbid cannabis use and other psychiatric disorders.

\section{Studies of Cannabis Withdrawal}

Symptoms of cannabis withdrawal include irritability, anxiety, restlessness, appetite changes, and disrupted sleep, ${ }^{40}$ and such symptoms may contribute to difficulty achieving or maintaining abstinence. Medications to treat cannabis withdrawal have been evaluated in a number of laboratory and small outpatient treatment studies. A summary of pharmacotherapy trials for cannabis withdrawal is shown in Table 3.

Antidepressants-An initial study evaluated the effects of sustained-release bupropion in non-treatment-seeking, heavy cannabis smokers. ${ }^{41}$ During a 12-day inpatient abstinence period, participants were randomized to receive bupropion or placebo. Participants receiving bupropion reported increased irritability, depressed mood, and sleep disturbances compared to participants receiving placebo. A small, recent, preliminary outpatient evaluation of bupropion reported more promising results; however, it should be noted that the sample size was small (9 participants). ${ }^{42}$ Using a paradigm similar to that used for cigarette smoking cessation, withdrawal symptoms were greater in placebo-treated participants, and cannabis craving increased in participants receiving placebo but not in those receiving bupropion.

Nefazodone was also been evaluated in an inpatient laboratory model. ${ }^{43}$ Nefazodone decreased reports of anxiety and muscle pain during cannabis withdrawal but did not reduce other withdrawal symptoms such as irritability and difficulty sleeping. The antidepressant mirtazapine improved abstinence-related sleep disruptions and increased appetite but did not affect mood symptoms of withdrawal or reduce relapse in a laboratory model. ${ }^{44}$ 
Cannabinoid Agonists-The oral cannabinoid agonist, delta-9-tetrahydrocannabinol (THC), has been evaluated in several studies for cannabis withdrawal symptoms. Oral THC $10 \mathrm{mg}$ administered 5 times daily decreased both withdrawal symptoms and cannabis craving in an inpatient laboratory study. ${ }^{45}$ An outpatient trial found oral THC at doses of 10 $\mathrm{mg} 3$ times daily and $30 \mathrm{mg} 3$ times daily to be effective in suppressing cannabis withdrawal symptoms. ${ }^{46}$ Of note, a follow-up human laboratory study found that the combination of oral THC and lofexidine, an $\mathrm{a}_{2}$-receptor agonist, may have synergistic effects for improving measures of withdrawal symptomatology as well as decreasing relapse in a laboratory model. ${ }^{47}$ The synthetic cannabinoid nabilone has also shown promise in laboratory evaluation, significantly attenuating withdrawal symptoms such as irritability and sleep disruptions while also reducing relapse behavior. ${ }^{48}$

Anticonvulsants and Mood Stabilizers-The mood stabilizer divalproex was shown to decrease cannabis craving during abstinence; however, its use was also associated with increased ratings of anxiety, irritability, sleepiness, and "bad effect." 45 In addition, divalproex administration worsened subject performance on psychomotor tasks and decreased social interactions. Although a small, open-label evaluation suggested some utility for lithium carbonate for management of cannabis withdrawal, ${ }^{49}$ a recent randomized, placebo-controlled trial conducted in an inpatient setting failed to show an effect of lithium treatment on withdrawal symptoms. ${ }^{50}$

Sedative-Hypnotics-The utility of extended-release zolpidem in targeting cannabis abstinence-induced sleep disruptions has been evaluated. ${ }^{51}$ Zolpidem attenuated the effects of cannabis abstinence on sleep architecture and normalized sleep efficiency scores but did not affect sleep latency. No significant differences in withdrawal symptoms were observed between participants during placebo-abstinence and zolpidem-abstinence periods.

Other Medication Classes-The $\gamma$-aminobutyric acid-B receptor agonist, baclofen, reduced cannabis craving during an active smoking paradigm but had limited impact on cannabis withdrawal symptoms in an inpatient laboratory evaluation. ${ }^{44}$ Baclofen also did not decrease measures of cannabis relapse. Quetiapine, an atypical antipsychotic, improved sleep quality and appetite during cannabis withdrawal but increased cannabis craving and relapse. ${ }^{52}$ As discussed above, lofexidine did not demonstrate utility on its own for cannabis withdrawal; however, the combination of lofexidine and oral THC significantly ameliorated cannabis withdrawal symptoms and decreased relapse in a laboratory model. ${ }^{47}$

\section{Pharmacotherapy for Treatment of Cannabis Use Disorders}

As with other dependencies, pharmacotherapy clinical trials for CUDs also generally incorporate other treatment modalities, such as CBT, MET, and CM therapies. Inclusion of a psychosocial platform provides all participants with some active treatment and may help with study retention. ${ }^{53}$ Medications evaluated for CUD treatment have largely mirrored the classes evaluated for cannabis withdrawal and have included antidepressants and anxiolytics, agonist therapy, and agents targeting specific neurotransmitters thought to be involved in addictive processes. A summary of clinical trials of pharmacotherapy for treatment of CUD is shown in Table 4. 
Antidepressants and Anxiolytics-Nefazodone and sustained-release bupropion were evaluated in a placebo-controlled trial of cannabis-dependent adults; neither medication had a significant effect on cannabis use or cannabis withdrawal symptoms. ${ }^{54} \mathrm{~A}$ recent study of escitalopram in an adult population also failed to find a positive effect of treatment on abstinence or withdrawal outcomes. ${ }^{55}$ Buspirone, a nonbenzodiazepine anxiolytic, showed limited preliminary evidence as a potential treatment for cannabis use disorders. ${ }^{56,57}$ However, a larger trial (175 subjects) found no significant difference in cannabis use outcomes in subjects receiving buspirone or placebo treatment; further, women randomized to buspirone treatment had significantly worse outcomes than men randomized to buspirone, suggesting a potential important gender differential in response to treatment ${ }^{58}$. A recent Cochrane review concluded that antidepressants and anxiolytics likely have limited value in the treatment of cannabis use disorders other than potentially for treatment of comorbid conditions. ${ }^{59}$

Cannabinoid Agonists-Based on the previously discussed data in cannabis withdrawal as well as the utility of agonist substitution therapy in other dependencies such as nicotine and opioid use disorders, dronabinol was evaluated in a large, randomized, double-blind, placebo-controlled trial for treatment of cannabis dependence. ${ }^{60}$ One hundred fifty-six cannabis-dependent adults received dronabinol or placebo over a 12-week period, and all participants received concomitant motivational enhancement and relapse prevention therapy. Both groups reported a reduction in cannabis use during the trial, and dronabinol was shown to improve retention in the trial and to reduce withdrawal symptoms. However, contrary to the hypothesis, there was not a medication effect of dronabinol on cannabis use. Although there is speculation about potential treatment roles for novel agonist compounds such as nabilone and nabixmols, to our knowledge, no clinical trials of these medications have been yet conducted for cannabis use disorder.

Anticonvulsants and Mood Stabilizers-Levin and colleagues conducted a randomized, double-blind, placebo-controlled, crossover study of the mood stabilizer divalproex in 25 cannabis-dependent adults; no significant effects of divalproex on psychological or cannabis use outcomes were observed. ${ }^{61}$ The anticonvulsant gabapentin was evaluated as a treatment in 50 cannabis-dependent individuals. ${ }^{62}$ Although the sample size was small and attrition relatively high with 18 participants completing the 8-week trial, gabapentin treatment resulted in significantly less cannabis use by both self-report and urine toxicology, significantly decreased cannabis withdrawal symptoms, and greater improvement in executive function compared to placebo treatment.

Glutamatergic Agents-To date, the most promising medication for treatment of cannabis use disorders is $N$-acetylcysteine (NAC), a prodrug of the naturally occurring amino acid cysteine. Through normalization of the cysteine-glutamate exchange process, NAC has been shown to reduce the reinstatement of drug seeking in animal models. An open-label trial of NAC in 24 young (aged 18-21 years) cannabis users demonstrated reductions in self-report of cannabis use and cannabis craving. ${ }^{63}$ A follow-up larger placebocontrolled study conducted in 116 participants showed that participants receiving NAC, when paired with brief counseling and CM to promote abstinence, had more than twice the 
odds of having negative urine cannabinoid tests during treatment compared to participants receiving placebo ${ }^{64} \mathrm{NAC}$ was also found to be well tolerated, with few adverse effects reported. A large multisite trial of NAC to extend these findings to an adult population was recently completed, and results are pending. ${ }^{65}$

\section{Treatment of Comorbidities}

The comorbidity of psychiatric and substance use disorders, including cannabis disorders, is associated with poor treatment prognosis. ${ }^{66-68}$ Importantly, improved substance abuse outcomes have been reported with pharmacologic treatment of co-occurring psychiatric disorders such as depression, anxiety disorders, and bipolar disorder. ${ }^{69-71}$ Cannabis use disorders have been significantly and positively associated with numerous Axis I and II disorders, including, but not limited to, bipolar disorders, depression, panic disorder, and generalized anxiety disorder. ${ }^{72}$

A limited number of studies have evaluated pharmacologic treatment of CUD in individuals with other psychiatric diagnoses. A secondary analysis found that fluoxetine treatment significantly reduced cannabis use in depressed, alcohol-dependent adults $;{ }^{73}$ however, a trial in adolescents and young adults with comorbid major depression and CUD did not find a significant effect of fluoxetine on cannabis-related outcomes. ${ }^{74}$ A recent trial examined the utility of extended-release venlafaxine combined with CBT for co-occurring cannabis dependence and depressive disorders. ${ }^{75}$ Venlafaxine was not better than placebo in reducing depressive symptoms, and, unexpectedly, participants receiving venlafaxine were less likely to reduce their cannabis use or become abstinent than participants receiving placebo. Finally, an evaluation of atomoxetine combined with MET on the symptoms of attention-deficit/ hyperactivity disorder (ADHD) and cannabis use in cannabis-dependent adults found limited improvement in ADHD measurements but no improvement on cannabis use outcomes. ${ }^{76}$

\section{Technologically Based Interventions}

Important technologically based interventions for CUD have been developed in recent years and is an emerging area. These computer and Internet-based treatments seek to improve service access, reduce training and delivery costs, ensure treatment fidelity, and enhance existing evidence-based approaches. ${ }^{77}$ Several studies have shown promising initial results.

Budney and colleagues developed a computer-delivered psychotherapy intervention (MET/CBT/CM) and compared it to an identical therapist-delivered version among 38 cannabis-dependent individuals. ${ }^{78}$ The computer-delivered intervention used three delivery techniques: computer-assisted instruction (e.g., provision of information requiring active responses), computer simulation (e.g., practicing drug refusal skills using video simulation), and interactive exercises and worksheets. All participants also received voucher-based CM incentives. Both groups improved on cannabis use outcomes, but importantly, there were no significant differences between therapist-delivered and computer-delivered treatments.

Although the results are promising, the study was limited by small sample size, lack of randomization, no control group, and no follow-up assessment to test durability.

Subsequently, Budney, Stanger, Tilford et al conducted a randomized clinical trial assigning 77 adults with cannabis use disorder to one of three conditions: a 2-session MET 
intervention (BRIEF), and 9-session MET/CBT intervention (THERAPIST), or an identical computer-delivered 9-session MET/CBT intervention (COMPUTER). ${ }^{79}$ End-of-treatment abstinence rates did not significantly differ between THERAPIST and COMPUTER, both of which were significantly higher than BRIEF. A similar pattern was observed for longest duration of continuous abstinence. Follow-up assessments revealed significantly higher abstinence rates for COMPUTER compared to BRIEF at 3 months after treatment, but not between THERAPIST and COMPUTER or THERAPIST and BRIEF. Relapse rates did not significantly differ across treatments over the 9-month follow-up period. Lastly, cost analysis revealed significantly greater cost per participant for THERAPIST (\$427) compared to COMPUTER (\$251) and BRIEF (\$171). These findings suggest comparable duringtreatment effects of computer- and therapist-delivered treatment, and enhanced durability of computer-delivered treatment at 3-month follow-up, all at reduced cost.

Computer-based interventions have shown effectiveness in individuals with comorbid depression and CUD as well. Kay-Lambkin and colleagues conducted a series of clinical trials examining computer-assisted MI/CBT vs. identical therapist-delivered MI/CBT vs. a 1-session brief intervention (BI). In the first study both computer- and therapist-assisted MI/CBT groups showed reductions in cannabis use and number of hazardous use days over the 12-month study and follow-up period compared to BI, but MI/CBT groups did not differ from one another. ${ }^{80}$ Computer-delivered treatment showed the largest overall treatment effects defined as percentage of participants "improved." A larger randomized trial conducted in 274 participants produced similar results, with both intervention groups showing greater reductions in cannabis use from baseline to 3 months compared to the control condition, but no significant differences between therapist- and computer-assisted treatments. ${ }^{81}$ Results lend further support for the potential utility and cost-effectiveness of computer-delivered therapy.

Other studies have examined Internet-based treatments for CUD. Rooke and colleagues conducted a two-arm, randomized clinical trial of an Internet-based, self-guided, self-help intervention called "Reduce Your Use" (RYU) ${ }^{82}$ RYU is a remotely administered, 6-module, self-guided intervention based on CBT and MI principles. Rooke et al. compared RYU to a 6-module educational control condition among 225 cannabis users. At the end of treatment, RYU participants reported fewer days and quantity of use in the past month compared to the control group, and reduction in days of use was maintained at 3 months. A similar study used online chats, diaries, and weekly online feedback as part of an Internet-based treatment for cannabis users seeking to quit or reduce their use ${ }^{83}$ Compared to a waitlist control group, the intervention showed greater reductions in days of use, quantity of use, and userelated self-efficacy at 3-month follow-up with large effect sizes. A major limitation in this study was the attrition rate (84\%), with only 206 of 1292 randomized participants completing the follow-up assessment, limiting interpretation of the findings.

Technological innovations have also been developed for treatment adherence, ecological assessment, and mobile intervention. The Interactive Voice Response (IVR) system involves completing CBT homework via telephone recording, which has been shown to enhance compliance and accuracy of reporting compared to paper-and-pencil form. ${ }^{84,} 85$ IVR has been employed in clinical trials for cannabis use disorder, ${ }^{15}$ as well as for alcohol 
dependence ${ }^{86}$ and chronic pain. ${ }^{87}$ In addition, ecological momentary assessment (EMA), which involves using a mobile device to prompt participants to complete in vivo assessments, has been used to examine environmental risk factors for using cannabis such as social anxiety, craving, and peer marijuana use ${ }^{88,89}$ and has been used in a variety of substance abuse treatment studies to date. Likewise, a mobile motivational intervention for cannabis users is currently under development. ${ }^{90}$

\section{Discussion}

\section{Efficacy of Treatment in Comparison to Other Dependencies}

Treatments for CUD have evolved over the past 15 years, yet more efficacious and durable treatments are needed. Results from clinical trials show moderate efficacy in reducing use but limited efficacy in achieving sustained abstinence. The most efficacious treatments to date include a combination of MET/CBT/CM including computer-delivered treatments, which show some of the highest abstinence rates to date. ${ }^{79}$ Comparative abstinence rates for psychosocial treatment of other substances are higher for alcohol use disorder ${ }^{91,92}$ and similar for cocaine, ${ }^{14,}{ }^{93}$ with one meta-analysis finding lower abstinence rates for cannabis users compared to cocaine, opiate, and polysubstance abusers. ${ }^{94}$ To date, no pharmacotherapeutic treatments for CUD have emerged as clearly efficacious, either independently or adjunctively. This is similar to challenges in developing pharmacotherapeutic interventions for cocaine dependence, ${ }^{95,}, 96$ yet in contrast to extensive evidence supporting pharmacotherapy for alcohol, opioid, and nicotine dependence.

\section{Barriers to Treatment Specific to Cannabis Users}

Approximately $10 \%$ of daily or near-daily cannabis users in the United States seek treatment (calculated from use and treatment data). ${ }^{1}$ This suggests vast undertreatment of a disorder with serious negative consequences. In studies comparing individuals with cannabis dependence who seek treatment with those who do not have an identified perceived lack of available and accessible treatment, barriers to care included the belief that treatment is not necessary, ambivalence or low motivation to change, fear of stigma, greater mental health problems, and desire for self-reliance. ${ }^{97-100}$ Furthermore, these barriers are not constant across individuals. When assessing perceived barriers to treatment among nearly 500 cannabis users from three samples (in treatment, in the community, and a widespread Internet sample), Gates and colleagues found that cannabis users currently in treatment identified intrinsic factors such as low motivation and difficulty admitting the need for help as barriers, whereas those in the community identified treatment-related factors such as lack of available treatment and confidentiality concerns as barriers. ${ }^{99}$ More frequent users reported wanting to avoid stigma, whereas females not in treatment reported that treatment was not necessary to stop using cannabis. Among long-term daily users who had achieved 1 year of sobriety, barriers included the belief that treatment was not necessary to quit, the problem did not warrant treatment, and stigma. ${ }^{98}$

Barriers also appear to differ among those expressing a desire for treatment compared to those who deem treatment unnecessary. Cannabis dependent individuals who denied the need for treatment expressed a desire for self-reliance and a preference for informal help, 
while those reporting subjective need also identified self-reliance, as well as perceived treatment ineffectiveness and avoidance of stigma. ${ }^{100}$ Importantly, potential facilitators of treatment seeking may include developing separate sites for CUD treatment, increasing availability of information on effective treatments, providing additional treatment options (e.g., telephone, computer-assisted), and simplifying admissions procedures. ${ }^{99}$

\section{Conclusion}

In light of the changing legal landscape regarding cannabis use in the United States, the prevalence rates of cannabis use and CUD have already begun to increase. Likewise, the number of people in need of treatment for CUD will likely rise. It is therefore crucial to continue pursuing effective treatments for CUD, specifically, new pharmacotherapeutic agents that can augment existing psychotherapeutic interventions. The potential upshot of marijuana legalization may be that there will be greater dialogue among the scientific community, the lay public, and governmental agencies. Ideally, this would lead to increased research funding, greater accessibility of findings, and heightened awareness not only of the consequences of heavy cannabis use but the availability of specific treatments.

\section{Acknowledgments}

Funding sources: Brian Sherman and Aimee McRae-Clark received funding for this article from (NIH grant nos. 5T32DA007288 and K24DA038240, respectively).

\section{References}

1. SAMHSA. Results from the 2013 National Survey on Drug Use and Health: Summary of National Findings. NSDUH Series H-48, HHS, Publication No (SMA) 14-4863. 2014 Government Document.

2. van der Pol P, Liebregts N, de Graaf R, Korf DJ, van den Brink W, van Laar M. The Dutch Cannabis Dependence (CanDep) study on the course of frequent cannabis use and dependence: Objectives, methods and sample characteristics. International Journal of Methods in Psychiatric Research. 2011; 3:169-81. [PubMed: 21815231]

3. Anthony JC, Warner LA, Kessler RC. Comparative epidemiology of dependence on tobacco, alcohol, controlled substances, and inhalants: Basic findings from the National Comorbidity Survey. Experimental and Clinical Psychopharmacology. 1994; 3:244-68.

4. Radhakrishnan R, Wilkinson ST, D'Souza DC. Gone to pot-A review of the association between cannabis and psychosis. Frontiers in Psychiatry. 2014

5. Crane N, Schuster R, Fusar-Poli P, Gonzalez R. Effects of Cannabis on Neurocognitive Functioning: Recent Advances, Neurodevelopmental Influences, and Sex Differences. Neuropsychol Rev. 2013; 2:117-37. [PubMed: 23129391]

6. Fergusson DM, Boden JM. Cannabis use and later life outcomes. Addiction. 2008; 6:969-76. [PubMed: 18482420]

7. Patton GC, Coffey C, Carlin JB, Degenhardt L, Lynskey M, Hall W. Cannabis use and mental health in young people: cohort study. BMJ : British Medical Journal. 2002; 7374:1195-98. [PubMed: 12446533]

8. American Psychiatric A, American Psychiatric A, Force DSMT. Diagnostic and statistical manual of mental disorders : DSM-5. Washington, D.C.: American Psychiatric Association; 2013.

9. Pew Research C. Debate over legalizing marijuana, disagreement over drug's dangers. 2015 Online Multimedia. 
10. Budney AJ, Moore BA, Rocha HL, Higgins ST. Clinical trial of abstinence-based vouchers and cognitive-behavioral therapy for cannabis dependence. Journal of consulting and clinical psychology. 2006; 2:307-16. [PubMed: 16649875]

11. Kadden RM, Litt MD, Kabela-Cormier E, Petry NM. Abstinence rates following behavioral treatments for marijuana dependence. Addictive behaviors. 2007; 6:1220-36. [PubMed: 16996224]

12. Marijuana Treatment Project Research G. Brief treatments for cannabis dependence: findings from a randomized multisite trial. Journal of consulting and clinical psychology. 2004; 3:455-66.

13. Budney AJ, Higgins ST, Radonovich KJ, Novy PL. Adding voucher-based incentives to coping skills and motivational enhancement improves outcomes during treatment for marijuana dependence. Journal of consulting and clinical psychology. 2000; 6:1051-61. [PubMed: 11142539]

14. Carroll KM, Nich C, Lapaglia DM, Peters EN, Easton CJ, Petry NM. Combining cognitive behavioral therapy and contingency management to enhance their effects in treating cannabis dependence: less can be more, more or less. Addiction. 2012; 9:1650-9. [PubMed: 22404223]

15. Litt MD, Kadden RM, Petry NM. Behavioral treatment for marijuana dependence: randomized trial of contingency management and self-efficacy enhancement. Addictive behaviors. 2013; 3:1764-75. [PubMed: 23254227]

16. Stephens RS, Roffman RA, Simpson EE. Treating adult marijuana dependence: A test of the relapse prevention model. Journal of consulting and clinical psychology. 1994; 1:92-99. [PubMed: 8034835]

17. Marlatt, GAG.; J, R. Relapse Prevention: Maintenance strategies in the treatment of addictive behaviors. New York: Guilford Press; 1985.

18. Stephens RS, Roffman RA, Curtin L. Comparison of extended versus brief treatments for marijuana use. Journal of consulting and clinical psychology. 2000; 5:898-908. [PubMed: 11068976]

19. Copeland J, Swift W, Roffman R, Stephens R. A randomized controlled trial of brief cognitivebehavioral interventions for cannabis use disorder. Journal of substance abuse treatment. 2001; 2:55-64. [PubMed: 11551733]

20. Miller, WR.; Rollnick, S. Motivational interviewing: Helping people change. 3rd. New York, NY, US: Guilford Press; 2013.

21. Stephens RS, Roffman RA, Fearer SA, Williams C, Burke RS. The Marijuana Check-up: Promoting change in ambivalent marijuana users. Addiction. 2007; 6:947-57. [PubMed: 17523990]

22. Stephens RS, Roffman RA, Fearer SA, Williams C, Picciano JF, Burke RS. The Marijuana Checkup: Reaching users who are ambivalent about change. Addiction. 2004; 10:1323-32. [PubMed: 15369571]

23. Miller WR, Benefield GS, Tonigan JS. Enhancing motivation for change in problem drinking: a controlled comparison of two therapist styles. Journal of consulting and clinical psychology. 1993:55-61.

24. Miller, WR.; Sovereign, RG. The check-up: a model for early intervention in addictive behaviors. In: Loberg, T.; Miller, Wr; Nathan, Pe; Marlatt, Ga, editors. Addictive behaviors: prevention and early intervention. 1989. p. 219-31.

25. Miller WR, Sovereign RG, Krege B. Motivational Interviewing with problem drinkers: II. The drinkers check-up as a preventive intervention. Behav Psychother. 1988:251-68.

26. Martin G, Copeland J. The adolescent cannabis check-up: Randomized trial of a brief intervention for young cannabis users. Journal of substance abuse treatment. 2008; 4:407-14. [PubMed: 17869051]

27. de Gee EA, Verdurmen JEE, Bransen E, de Jonge JM, Schippers GM. A randomized controlled trial of a brief motivational enhancement for non-treatment-seeking adolescent cannabis users. Journal of substance abuse treatment. 2014; 3:181-88. [PubMed: 24969735]

28. McCambridge J, Slym RL, Strang J. Randomized controlled trial of motivational interviewing compared with drug information and advice for early intervention among young cannabis users. Addiction. 2008; 11:1809-18. [PubMed: 18778385] 
29. McCambridge J, Day M, Thomas BA, Strang J. Fidelity to Motivational Interviewing and subsequent cannabis cessation among adolescents. Addictive behaviors. 2011; 7:749-54. [PubMed: 21440994]

30. Flory K, Lynam D, Milich R, Leukefeld C, Clayton R. Early adolescent through young adult alcohol and marijuana use trajectories: Early predictors, young adult outcomes, and predictive utility. Development and Psychopathology. 2004; 1:193-213. [PubMed: 15115071]

31. Brady KT, Randall CL. Gender differences in substance use disorders. Psychiatric Clinics of North America. 1999; 2:241-52. [PubMed: 10385931]

32. Greenfield SF, Manwani SG, Nargiso JE. Epidemiology of substance use disorders in women. Obstetrics and Gynecology Clinics of North America. 2003; 3:414-46.

33. Stein MD, Hagerty CE, Herman DS, Phipps MG, Anderson BJ. A brief marijuana intervention for non-treatment-seeking young adult women. Journal of substance abuse treatment. 2011; 2:189-98. [PubMed: 21185685]

34. Dennis M, Godley SH, Diamond G, et al. The Cannabis Youth Treatment (CYT) Study: Main findings from two randomized trials. Journal of substance abuse treatment. 2004; 3:197-213. [PubMed: 15501373]

35. Walker DD, Stephens RS, Towe S, Banes K, Roffman R. Maintenance Check-ups Following Treatment for Cannabis Dependence. Journal of substance abuse treatment. 2015:11-5. [PubMed: 25922136]

36. Carroll KM, Easton CJ, Nich C, et al. The use of contingency management and motivational/skillsbuilding therapy to treat young adults with marijuana dependence. Journal of consulting and clinical psychology. 2006; 5:955-66. [PubMed: 17032099]

37. Liddle HA, Dakof GA, Turner RM, Henderson CE, Greenbaum PE. Treating adolescent drug abuse: a randomized trial comparing multidimensional family therapy and cognitive behavior therapy. Addiction. 2008; 10:1660-70. [PubMed: 18705691]

38. Hendriks V, van der Schee E, Blanken P. Treatment of adolescents with a cannabis use disorder: main findings of a randomized controlled trial comparing multidimensional family therapy and cognitive behavioral therapy in The Netherlands. Drug and alcohol dependence. 2011; 1-2:64-71. [PubMed: 21684088]

39. de Dios MA, Herman DS, Britton WB, Hagerty CE, Anderson BJ, Stein MD. Motivational and mindfulness intervention for young adult female marijuana users. Journal of substance abuse treatment. 2012; 1:56-64. [PubMed: 21940136]

40. Budney AJ, Hughes JR. The cannabis withdrawal syndrome. Current opinion in psychiatry. 2006; 3:233-8. [PubMed: 16612207]

41. Haney M, Ward AS, Comer SD, Hart CL, Foltin RW, Fischman MW. Bupropion SR worsens mood during marijuana withdrawal in humans. Psychopharmacology. 2001; 2:171-9. [PubMed: 11401006]

42. Penetar DM, Looby AR, Ryan ET, Maywalt MA, Lukas SE. Bupropion reduces some of the symptoms of marihuana withdrawal in chronic marihuana users: a pilot study. Substance abuse : research and treatment. 2012:63-71. [PubMed: 22879754]

43. Haney M, Hart CL, Ward AS, Foltin RW. Nefazodone decreases anxiety during marijuana withdrawal in humans. Psychopharmacology. 2003; 2:157-65. [PubMed: 12439626]

44. Haney M, Hart CL, Vosburg SK, et al. Effects of baclofen and mirtazapine on a laboratory model of marijuana withdrawal and relapse. Psychopharmacology. 2010; 2:233-44. [PubMed: 20521030]

45. Haney M, Hart CL, Vosburg SK, et al. Marijuana withdrawal in humans: effects of oral THC or divalproex. Neuropsychopharmacology : official publication of the American College of Neuropsychopharmacology. 2004; 1:158-70. [PubMed: 14560320]

46. Budney AJ, Vandrey RG, Hughes JR, Moore BA, Bahrenburg B. Oral delta-9-tetrahydrocannabinol suppresses cannabis withdrawal symptoms. Drug and alcohol dependence. 2007; 1:22-9. [PubMed: 16769180]

47. Haney M, Hart CL, Vosburg SK, Comer SD, Reed SC, Foltin RW. Effects of THC and lofexidine in a human laboratory model of marijuana withdrawal and relapse. Psychopharmacology. 2008; 1:157-68. [PubMed: 18161012] 
48. Haney M, Cooper ZD, Bedi G, Vosburg SK, Comer SD, Foltin RW. Nabilone decreases marijuana withdrawal and a laboratory measure of marijuana relapse. Neuropsychopharmacology : official publication of the American College of Neuropsychopharmacology. 2013:1557-65. [PubMed: 23443718]

49. Winstock AR, Lea T, Copeland J. Lithium carbonate in the management of cannabis withdrawal in humans: an open-label study. Journal of psychopharmacology. 2009; 1:84-93. [PubMed: 18515451]

50. Johnston J, Lintzeris N, Allsop DJ, et al. Lithium carbonate in the management of cannabis withdrawal: a randomized placebo-controlled trial in an inpatient setting. Psychopharmacology. 2014

51. Vandrey R, Smith MT, McCann UD, Budney AJ, Curran EM. Sleep disturbance and the effects of extended-release zolpidem during cannabis withdrawal. Drug and alcohol dependence. 2011; 1:38-44. [PubMed: 21296508]

52. Cooper ZD, Foltin RW, Hart CL, Vosburg SK, Comer SD, Haney M. A human laboratory study investigating the effects of quetiapine on marijuana withdrawal and relapse in daily marijuana smokers. Addiction biology. 2013; 6:993-1002. [PubMed: 22741619]

53. Carroll KM, Kosten TR, Rounsaville BJ. Choosing a behavioral therapy platform for pharmacotherapy of substance users. Drug and alcohol dependence. 2004; 2:123-34. [PubMed: 15276217]

54. Carpenter KM, McDowell D, Brooks DJ, Cheng WY, Levin FR. A preliminary trial: double-blind comparison of nefazodone, bupropion-SR, and placebo in the treatment of cannabis dependence. The American journal on addictions / American Academy of Psychiatrists in Alcoholism and Addictions. 2009; 1:53-64. [PubMed: 19219666]

55. Weinstein AM, Miller H, Bluvstein I, et al. Treatment of cannabis dependence using escitalopram in combination with cognitive-behavior therapy: a double-blind placebo-controlled study. The American journal of drug and alcohol abuse. 2014; 1:16-22. [PubMed: 24359507]

56. McRae AL, Brady KT, Carter RE. Buspirone for treatment of marijuana dependence: a pilot study. The American journal on addictions / American Academy of Psychiatrists in Alcoholism and Addictions. 2006; 5:404. [PubMed: 16966201]

57. McRae-Clark AL, Carter RE, Killeen TK, et al. A placebo-controlled trial of buspirone for the treatment of marijuana dependence. Drug and alcohol dependence. 2009; 1-2:132-8. [PubMed: 19699593]

58. McRae-Clark AL, Baker NL, Gray KM, et al. Buspirone treatment of cannabis dependence: A randomized, placebo-controlled trial. Drug and alcohol dependence. 2015:29-37. [PubMed: 26386827]

59. Marshall K, Gowing L, Ali R, Le Foll B. Pharmacotherapies for cannabis dependence. The Cochrane database of systematic reviews. 2014:Cd008940. [PubMed: 25515775]

60. Levin FR, Mariani JJ, Brooks DJ, Pavlicova M, Cheng W, Nunes EV. Dronabinol for the treatment of cannabis dependence: a randomized, double-blind, placebo-controlled trial. Drug and alcohol dependence. 2011; 1-3:142-50. [PubMed: 21310551]

61. Levin FR, McDowell D, Evans SM, et al. Pharmacotherapy for marijuana dependence: a doubleblind, placebo-controlled pilot study of divalproex sodium. The American journal on addictions / American Academy of Psychiatrists in Alcoholism and Addictions. 2004; 1:21-32. [PubMed: 14766435]

62. Mason BJ, Crean R, Goodell V, et al. A proof-of-concept randomized controlled study of gabapentin: effects on cannabis use, withdrawal and executive function deficits in cannabisdependent adults. Neuropsychopharmacology : official publication of the American College of Neuropsychopharmacology. 2012; 7:1689-98. [PubMed: 22373942]

63. Gray KM, Watson NL, Carpenter MJ, Larowe SD. N-acetylcysteine (NAC) in young marijuana users: an open-label pilot study. The American journal on addictions / American Academy of Psychiatrists in Alcoholism and Addictions. 2010; 2:187-9. [PubMed: 20163391]

64. Gray KM, Carpenter MJ, Baker NL, et al. A double-blind randomized controlled trial of Nacetylcysteine in cannabis-dependent adolescents. The American journal of psychiatry. 2012; 8:805-12. [PubMed: 22706327] 
65. McClure EA, Gipson CD, Malcolm RJ, Kalivas PW, Gray KM. Potential Role of N-Acetylcysteine in the Management of Substance Use Disorders. CNS drugs. 2014; 2:95-106. [PubMed: 24442756]

66. Rounsaville BJ, Anton SF, Carroll K, Budde D, Prusoff BA, Gawin F. Psychiatric diagnoses of treatment-seeking cocaine abusers. Archives of general psychiatry. 1991; 1:43-51. [PubMed: 1984761]

67. Rounsaville BJ, Weissman MM, Crits-Christoph K, Wilber C, Kleber H. Diagnosis and symptoms of depression in opiate addicts. Course and relationship to treatment outcome. Archives of general psychiatry. 1982; 2:151-6. [PubMed: 7065829]

68. Strakowski SM, Tohen M, Stoll AL, Faedda GL, Goodwin DC. Comorbidity in mania at first hospitalization. The American journal of psychiatry. 1992; 4:554-6. [PubMed: 1348163]

69. Brady KT, Sonne SC, Anton R, Ballenger JC. Valproate in the treatment of acute bipolar affective episodes complicated by substance abuse: a pilot study. The Journal of clinical psychiatry. 1995; 3:118-21. [PubMed: 7883730]

70. Kranzler HR, Burleson JA, Del Boca FK, et al. Buspirone treatment of anxious alcoholics. A placebo-controlled trial. Archives of general psychiatry. 1994; 9:720-31. [PubMed: 8080349]

71. Nunes EV, Quitkin FM, Donovan SJ, et al. Imipramine treatment of opiate-dependent patients with depressive disorders. A placebo-controlled trial. Archives of general psychiatry. 1998; 2:153-60. [PubMed: 9477929]

72. Stinson FS, Ruan WJ, Pickering R, Grant BF. Cannabis use disorders in the USA: prevalence, correlates and co-morbidity. Psychological medicine. 2006; 10:1447-60. [PubMed: 16854249]

73. Cornelius JR, Salloum IM, Haskett RF, et al. Fluoxetine versus placebo for the marijuana use of depressed alcoholics. Addictive behaviors. 1999; 1:111-4. [PubMed: 10189977]

74. Cornelius JR, Bukstein OG, Douaihy AB, et al. Double-blind fluoxetine trial in comorbid MDDCUD youth and young adults. Drug and alcohol dependence. 2010; 1-2:39-45. [PubMed: 20576364]

75. Levin FR, Mariani J, Brooks DJ, et al. A randomized double-blind, placebo-controlled trial of venlafaxine-extended release for co-occurring cannabis dependence and depressive disorders. Addiction. 2013; 6:1084-94. [PubMed: 23297841]

76. McRae-Clark AL, Carter RE, Killeen TK, Carpenter MJ, White KG, Brady KT. A placebocontrolled trial of atomoxetine in marijuana-dependent individuals with attention deficit hyperactivity disorder. The American journal on addictions / American Academy of Psychiatrists in Alcoholism and Addictions. 2010; 6:481-9. [PubMed: 20958842]

77. Marsch LA, Carroll KM, Kiluk BD. Technology-based interventions for the treatment and recovery management of substance use disorders: a JSAT special issue. Journal of substance abuse treatment. 2014; 1:1-4. [PubMed: 24041749]

78. Budney AJ, Fearer S, Walker DD, et al. An initial trial of a computerized behavioral intervention for cannabis use disorder. Drug and alcohol dependence. 2011; 1-2:74-9. [PubMed: 21131143]

79. Budney AJ, Stanger C, Tilford JM, et al. Computer-Assisted Behavioral Therapy and Contingency Management for Cannabis Use Disorder. Psychology of addictive behaviors : journal of the Society of Psychologists in Addictive Behaviors. 2015

80. Kay-Lambkin FJ, Baker AL, Lewin TJ, Carr VJ. Computer-based psychological treatment for comorbid depression and problematic alcohol and/or cannabis use: a randomized controlled trial of clinical efficacy. Addiction. 2009; 3:378-88. [PubMed: 19207345]

81. Kay-Lambkin F, Baker A, Kelly B, Lewin T. Clinician assisted computerized versus therapist delivered treatment for depressive and addictive disorders: a randomized controlled trial. MJA. 2011:S44. [PubMed: 21806518]

82. Rooke S, Copeland J, Norberg M, Hine D, McCambridge J. Effectiveness of a self-guided webbased cannabis treatment program: randomized controlled trial. Journal of medical Internet research. 2013; 2:e26. [PubMed: 23470329]

83. Tossmann HP, Jonas B, Tensil MD, Lang P, Struber E. A controlled trial of an internet-based intervention program for cannabis users. Cyberpsychology, behavior and social networking. 2011; 11:673-9. 
84. Corkrey R, Parkinson L. Interactive voice response: review of studies 1989-2000. Behav Res Methods. 2002; 3:342-53.

85. Searles JS, Helzer JE, Rose GI, et al. Concurrent and retrospective reports of alcohol consumption across 30, 90, and 366 days: interactive voice response compared with the timeline follow back. J Stud Alcohol. 2002:352-62. [PubMed: 12086136]

86. Rose GL, Skelly JM, Badger GJ, Ferraro TA, Helzer JE. Efficacy of automated telephone continuing care following outpatient therapy for alcohol dependence. Addictive behaviors. 2015:223-31. [PubMed: 25452069]

87. Naylor MR, Keefe FJ, Brigidi B, et al. Therapeutic interactive voice response for chronic pain reduction and relapse prevention. Pain. 2008; 3:335-45. [PubMed: 18178011]

88. Buckner JD, Crosby RD, Silgado J, Wonderlich SA, Schmidt NB. Immediate antecedents of marijuana use: an analysis from ecological momentary assessment. Journal of behavior therapy and experimental psychiatry. 2012; 1:647-55. [PubMed: 21946296]

89. Buckner JD, Crosby RD, Wonderlich SA, Schmidt NB. Social anxiety and cannabis use: an analysis from ecological momentary assessment. Journal of anxiety disorders. 2012; 2:297-304. [PubMed: 22246109]

90. Shrier LA, Rhoads A, Burke P, Walls C, Blood EA. Real-time, contextual intervention using mobile technology to reduce marijuana use among youth: A pilot study. Addictive behaviors. 2014; 1:173-80. [PubMed: 24139665]

91. Group PMR. Matching alcoholism treatments to client heterogeneity: Project MATCH Posttreatment drinking outcomes. Journal of Studies on Alcohol. 1997; 1:7-29.

92. Group PMR. Matching alcoholism treatments to client heterogeneity: Project MATCH three-year drinking outcomes. Alcoholism: Clinical and Experimental Research. 1998; 6:1300-11.

93. Carroll KM, Kiluk BD, Nich C, et al. Computer-assisted delivery of cognitive-behavioral therapy: Efficacy and durability of CBT4CBT among cocaine-dependent individuals maintained on methadone. American journal of Psychiatry. 2014:436-44. [PubMed: 24577287]

94. Dutra L, Stathopoulou G, Basden SL, Leyro TM, Powers MB, Otto MW. A meta analytic review of psychosocial interventions for substance use disorders. American Journal of Psychiatry. 2008:17987. [PubMed: 18198270]

95. Nuijten M, Blanken P, van den Brink W, Hendriks V. Treatment of crack-cocaine dependence with topiramate: A randomized controlled feasibility trial in the Netherlands. Drug and alcohol dependence. 2014:177-84. [PubMed: 24629631]

96. Tapp A, Wood AE, Kennedy A, Sylvers P, Kilzieh N, Saxon AJ. Quetiapine for the treatment of cocaine use disorder. Drug and alcohol dependence. 2015:18-24. [PubMed: 25682480]

97. Budney AJ, Radonovich KJ, Higgins ST, et al. Adults seeking treatment for marijuana dependence: a comparison with cocaine-dependent treatment seekers. Exp Clin Psychopharmacol. 1998:41926. [PubMed: 9861556]

98. Ellingstad TP, Sobell LC, Sobell MB, Eickleberry L, Golden CJ. Self-change: A pathway to cannabis abuse resolution. Addictive behaviors. 2006:519-30. [PubMed: 15967588]

99. Gates P, Copeland J, Swift W, Martin G. Barriers and facilitators to cannabis treatment. Drug and Alcohol Review. 2012:311-19. [PubMed: 21521384]

100. van der Pol P, Liebregts N, de Graaf R, Korf DJ, van den Brink W, van Laar M. Predicting the transition from frequent cannabis use to cannabis dependence: a three-year prospective study. Drug and alcohol dependence. 2013; 2:352-9. [PubMed: 23886472] 


\section{Table 1}

Diagnostic Criteria for Cannabis Use Disorder. Diagnostic and Statistical Manual of Mental Disorders - Fifth Edition $(D S M-5)^{8}$.

Problematic pattern of use, leading to clinically significant impairment or distress, manifested by at least 2 of the following, occurring within a 12-month period:

- The substance is taken in larger amounts or over a longer period than was intended.

- Persistent desire or unsuccessful effort to cut down or control use.

- Great deal of time spent obtaining, using, or recovering from the effects of cannabis.

- Craving, or a strong desire or urge to use cannabis.

- Rucurrent use resulting in failure to fulfill major obligations at work, school, or home.

- Continued use despite having persistent or recurrent social or interpersonal problems caused by or exacerbated by the effects of use.

- Giving up or reducing important social, occupational, or recreational activities because of use.

- Recurrent use in situations that could be physically hazardous.

- Continued use despite knowledge of having a persistent or recurrent physical or psychological problem caused by or exacerbated by use.

- Need for markedly increased amounts of the substance to achieved intoxication or desired effect; or diminished effect with continued use of the same amount.

- Characteristic withdrawal syndrome for the substance (see below); or the substance is taken to relieve or avoid withdrawal symptoms. Severity indicators:

$2-3$ criteria met $=$ Mild

4-5 criteria met $=$ Moderate

6 or more criteria $=$ Severe

Cannabis withdrawal syndrome symptom checklist ( 3 or more):

1. irritability, anger, or agression

2. nervousness or anxiety

3. trouble sleeping

4. appetite or weight loss

5. resltessness

6. feeling depressed

7. significant discomfort from one of the following: stomach pain, tremors or shakes, sweating, hot flashes, chills, headaches 


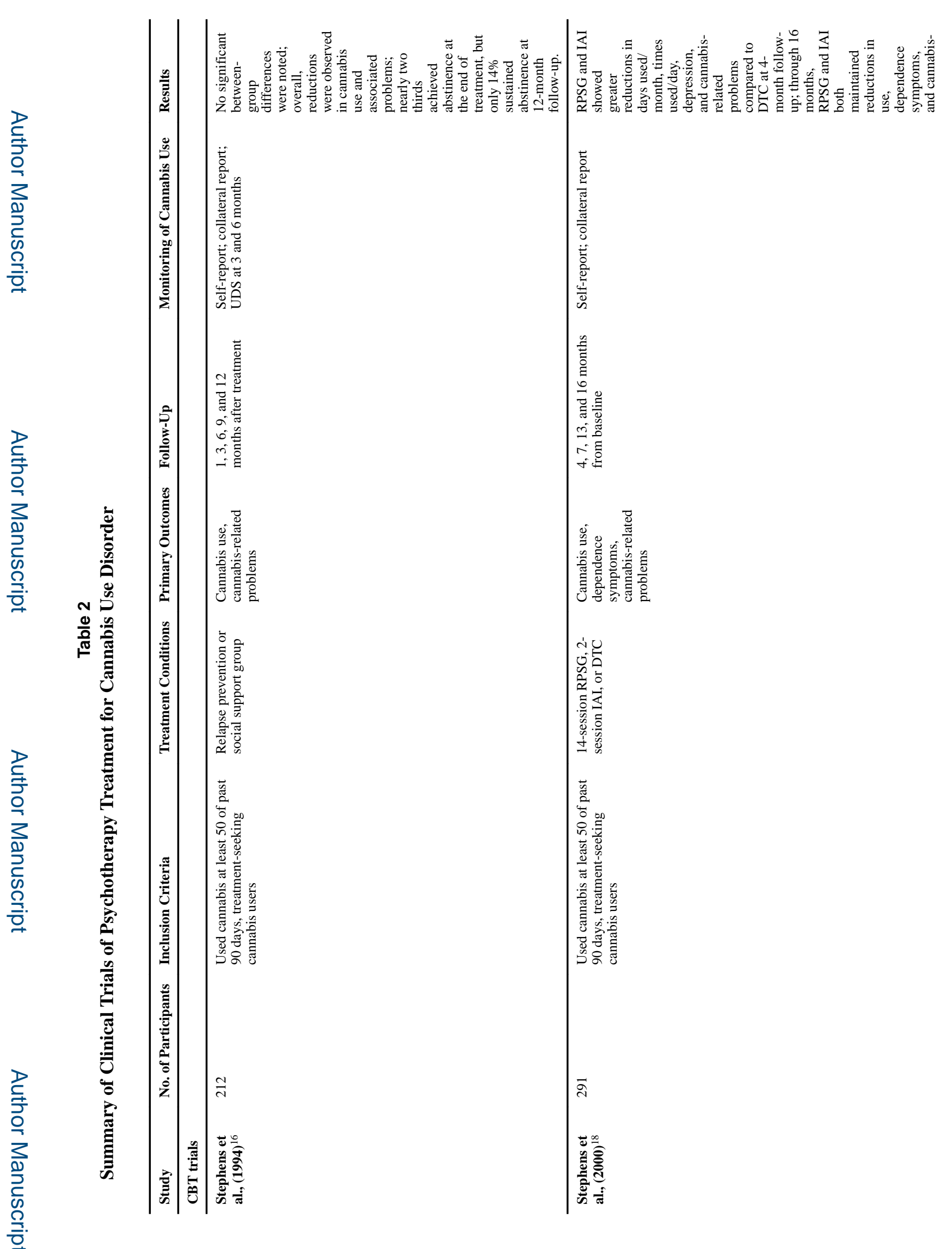

Pharmacotherapy. Author manuscript; available in PMC 2017 May 01. 


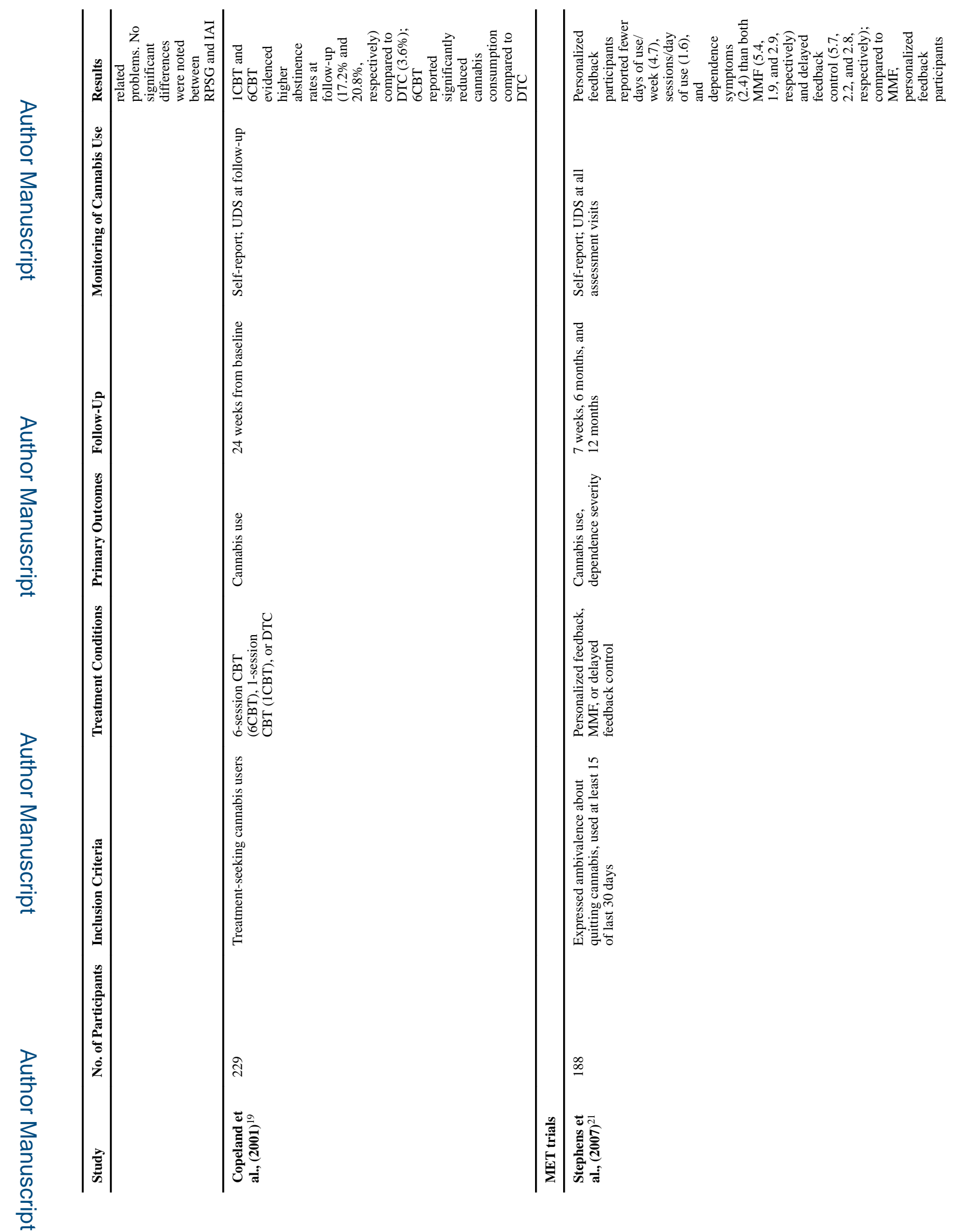


Sherman and McRae-Clark

Page 24

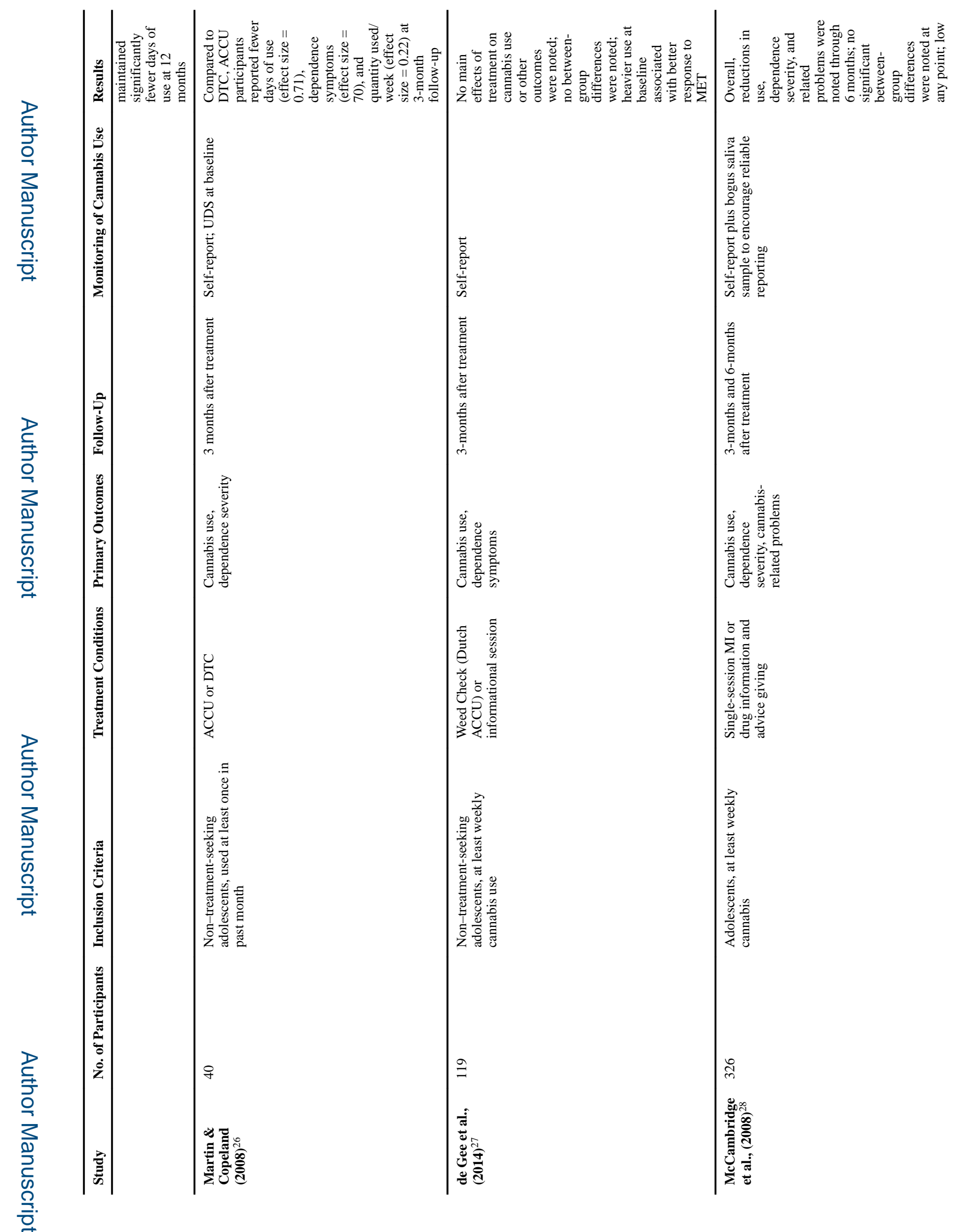

Pharmacotherapy. Author manuscript; available in PMC 2017 May 01. 


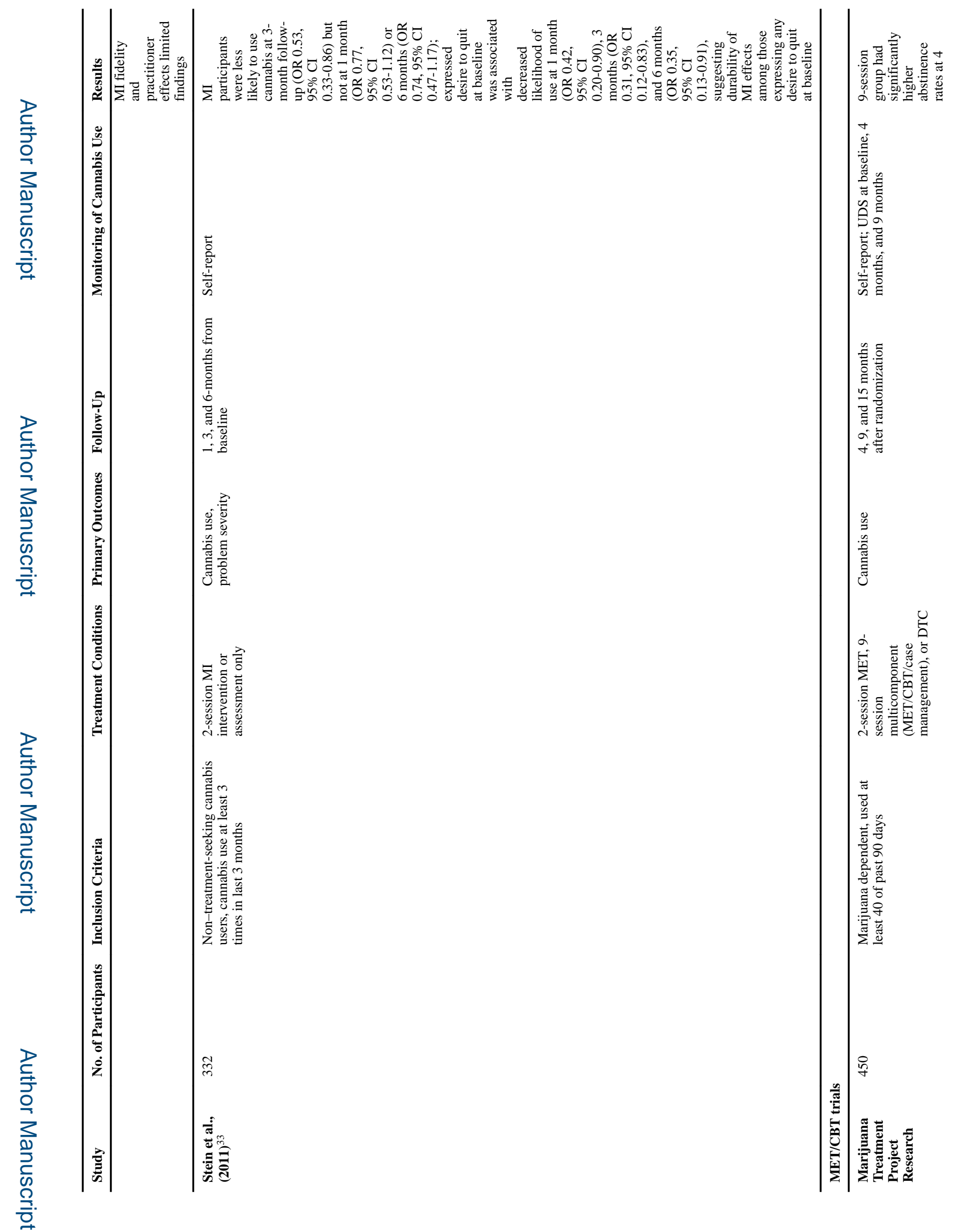

Pharmacotherapy. Author manuscript; available in PMC 2017 May 01. 


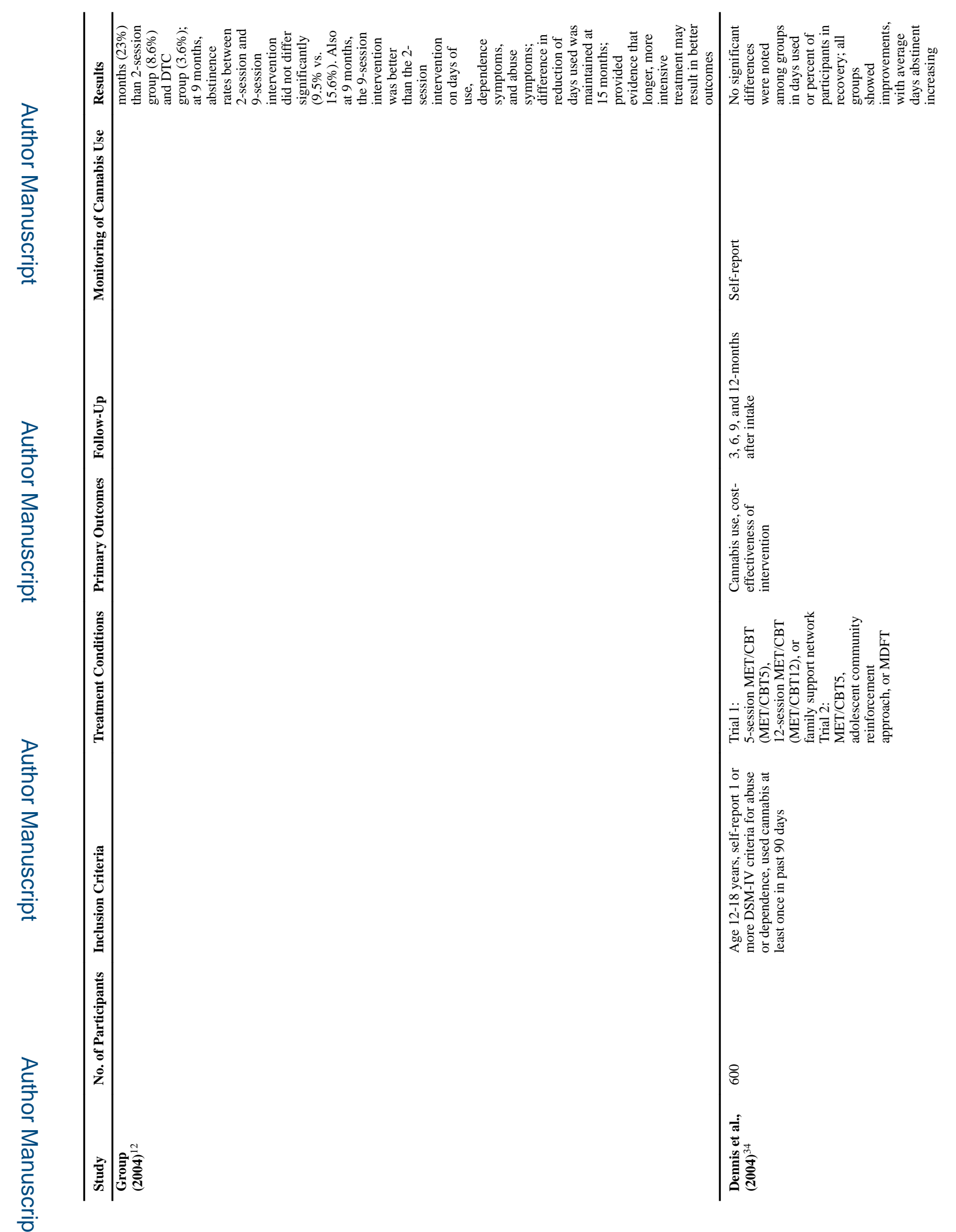




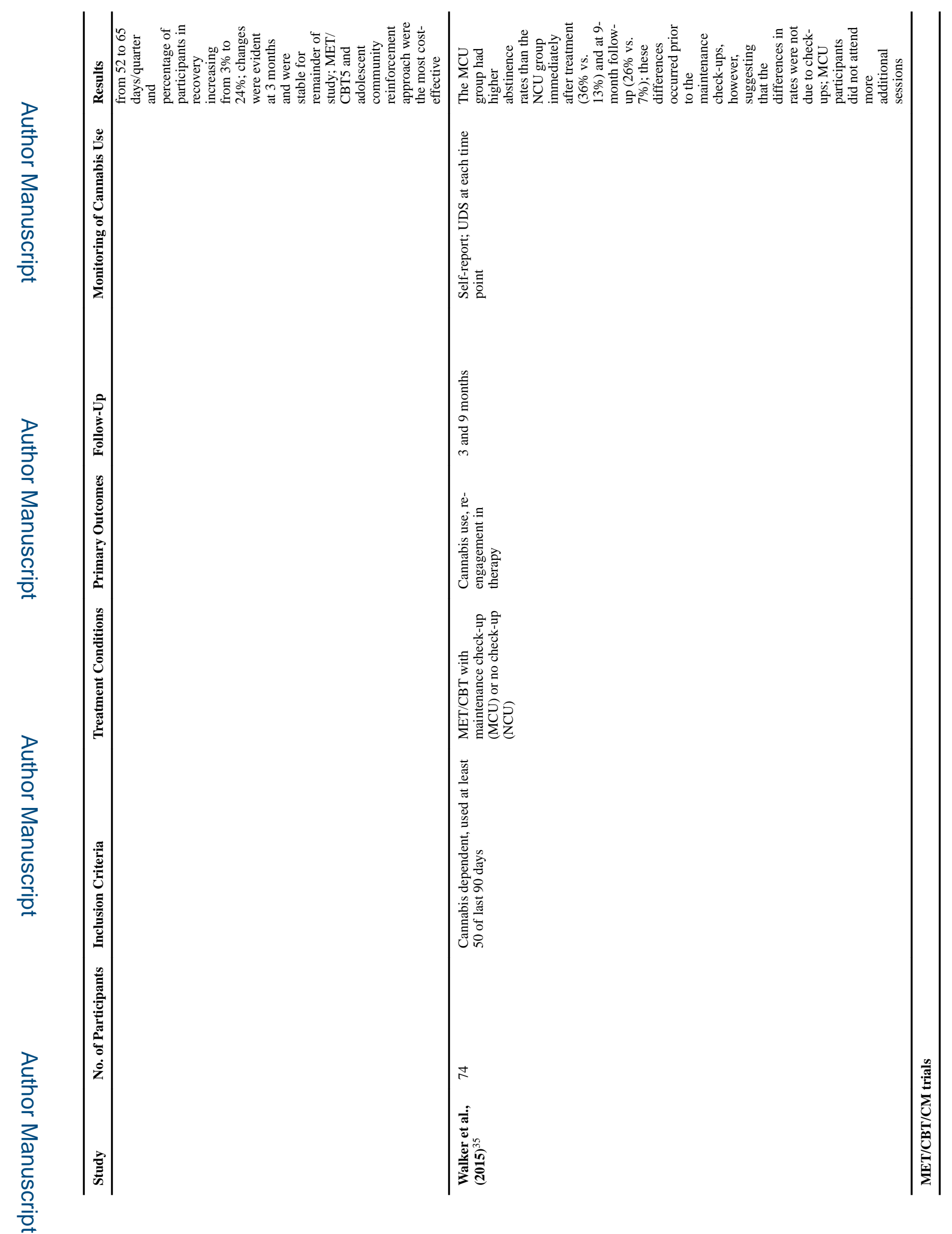




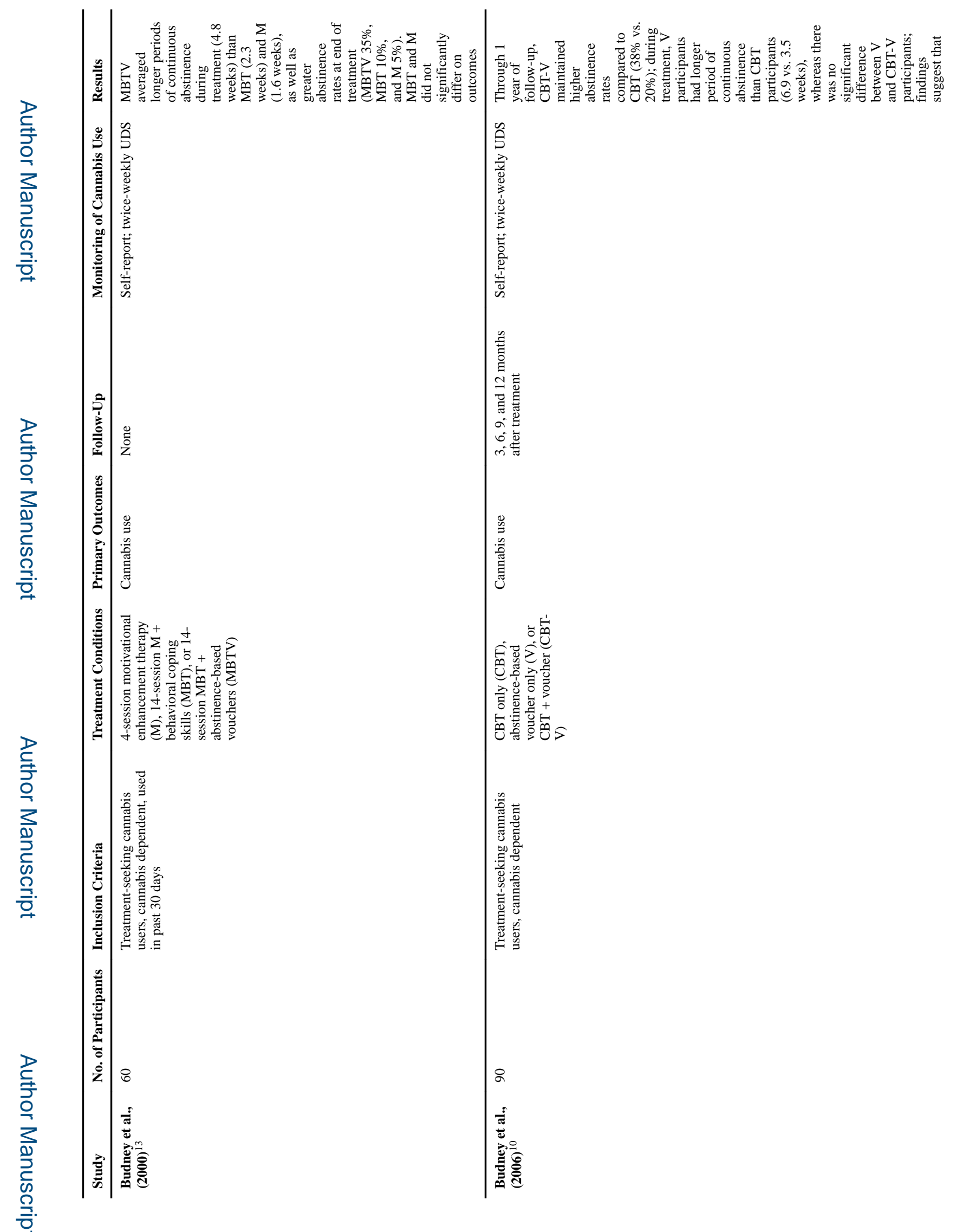




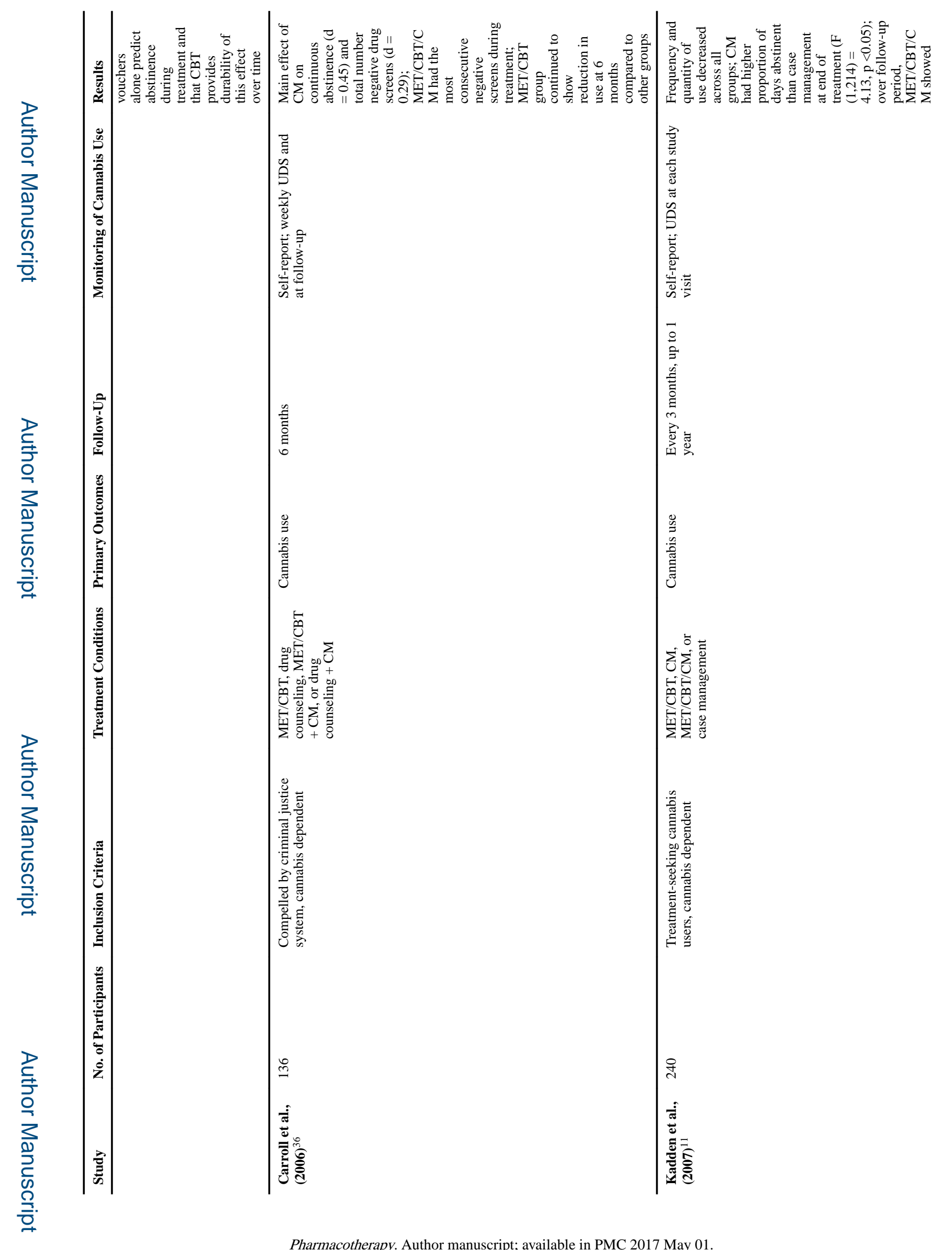




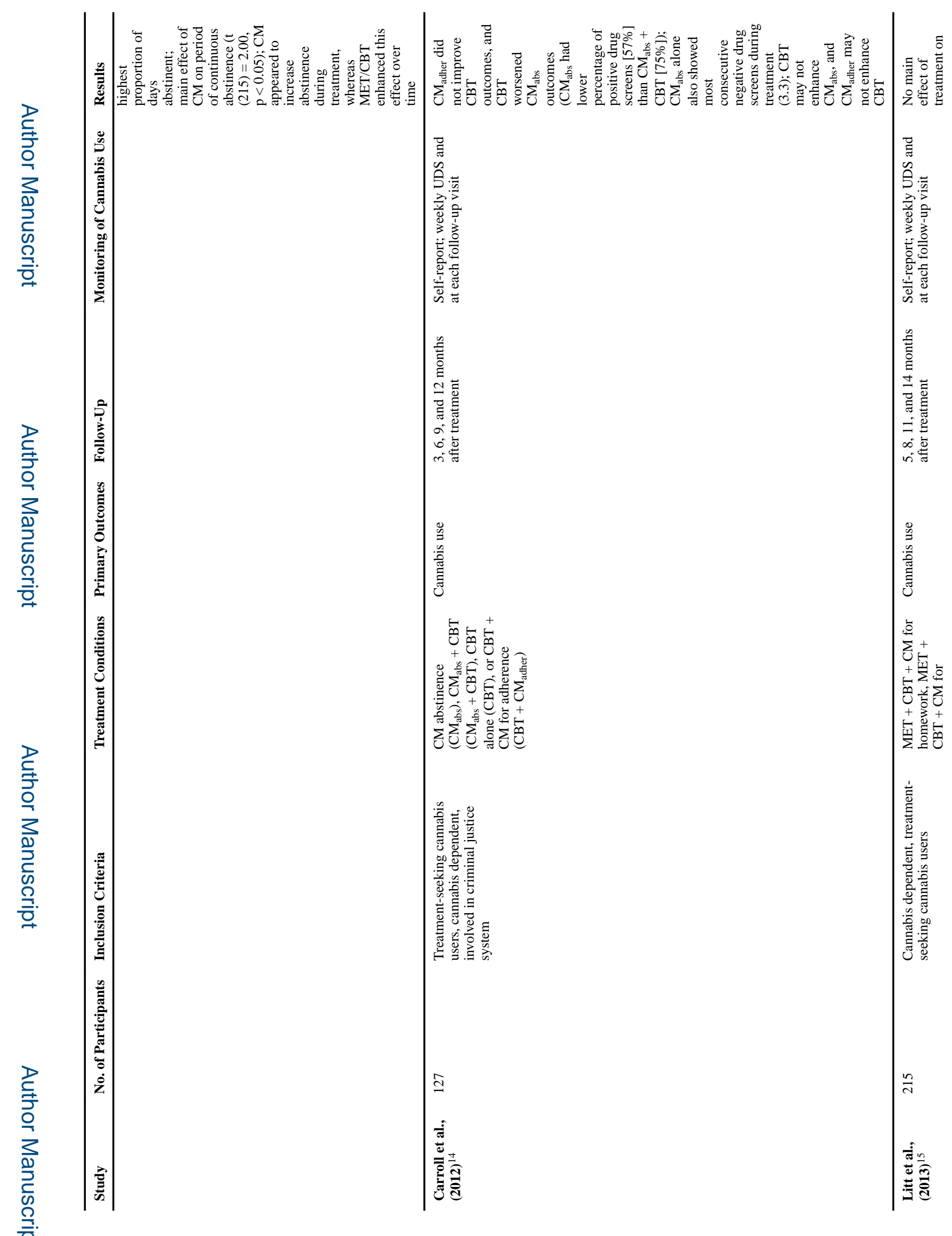


Sherman and McRae-Clark

Page 31

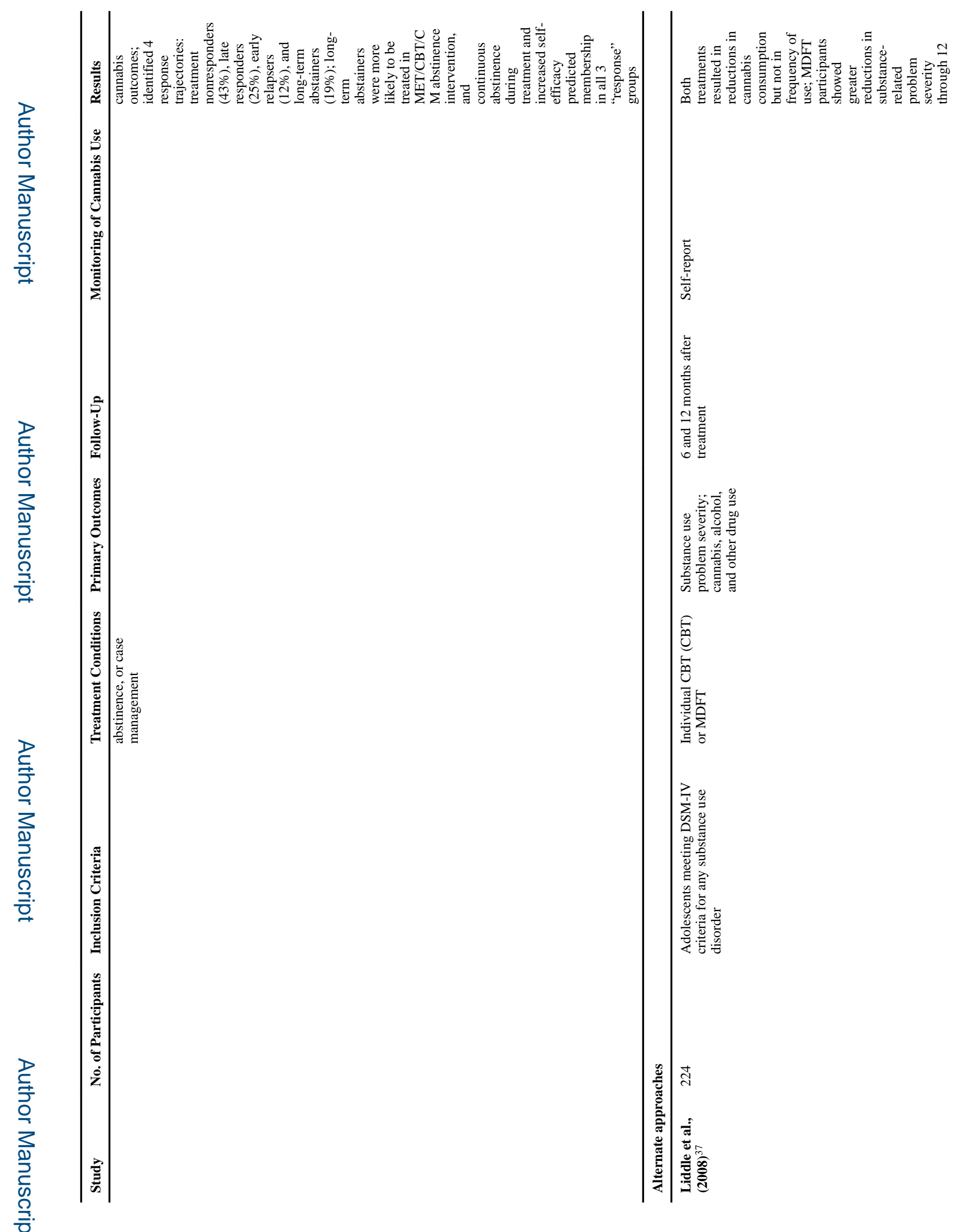

Pharmacotherapy. Author manuscript; available in PMC 2017 May 01. 


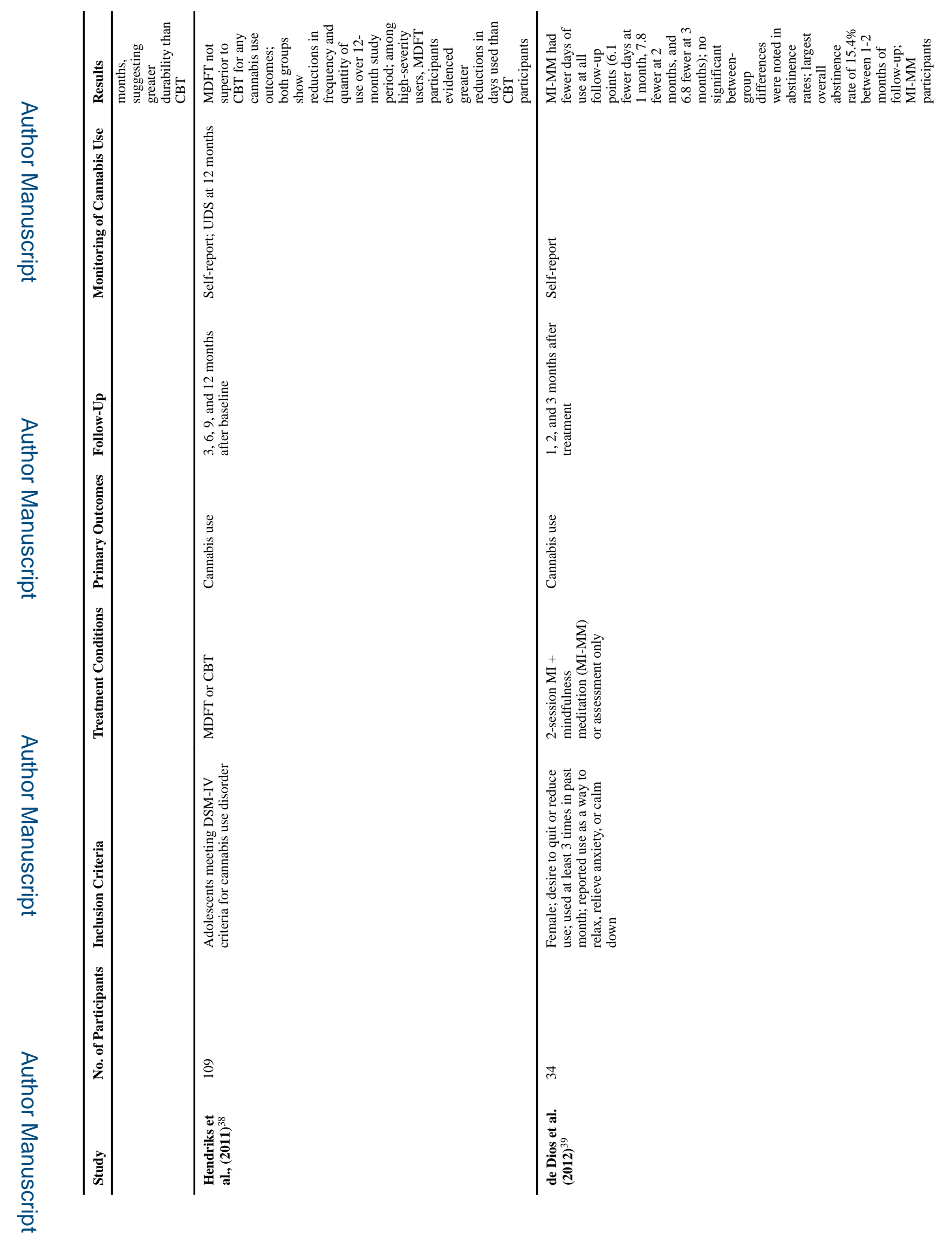


Sherman and McRae-Clark

Page 33

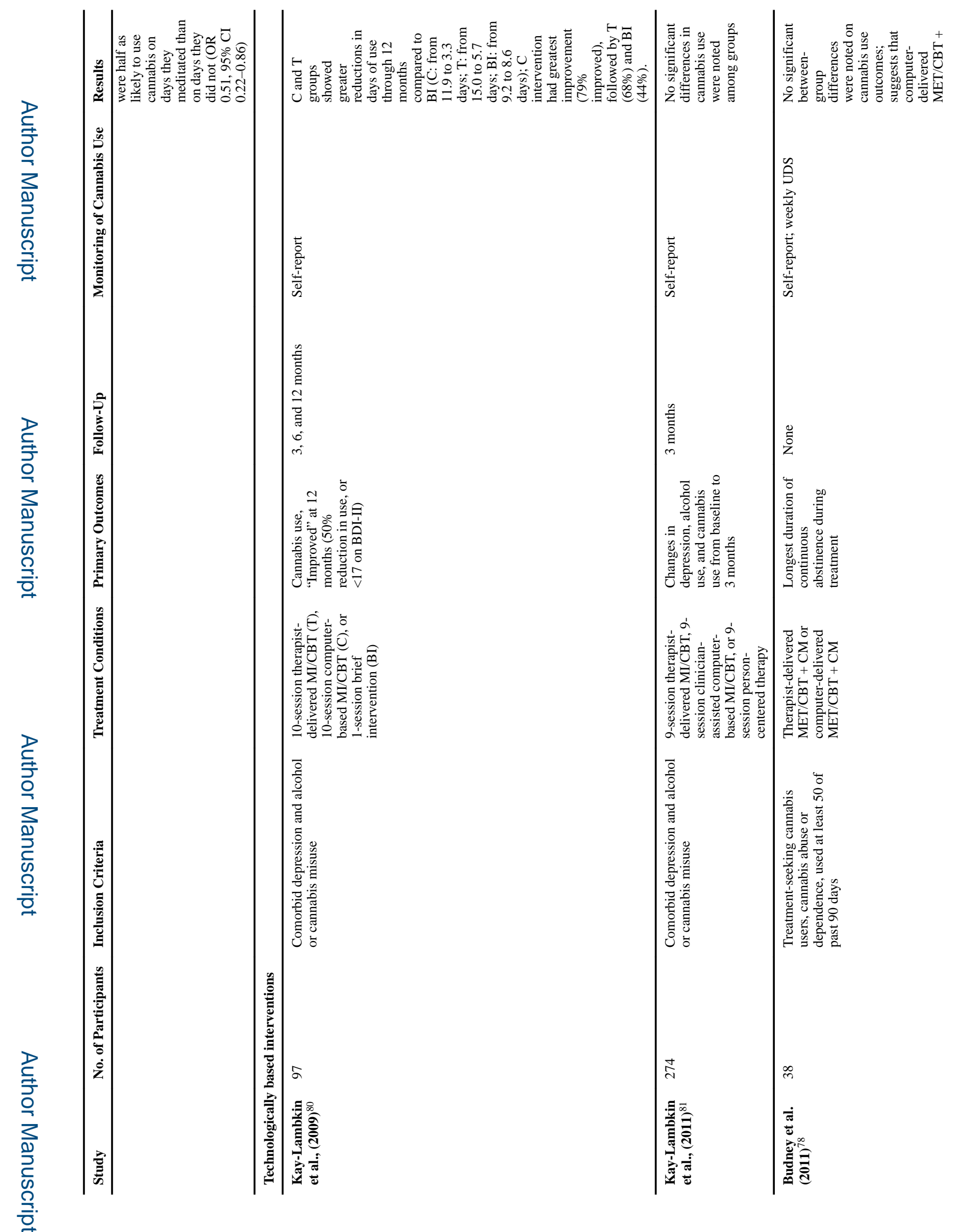

Pharmacotherapy. Author manuscript; available in PMC 2017 May 01. 


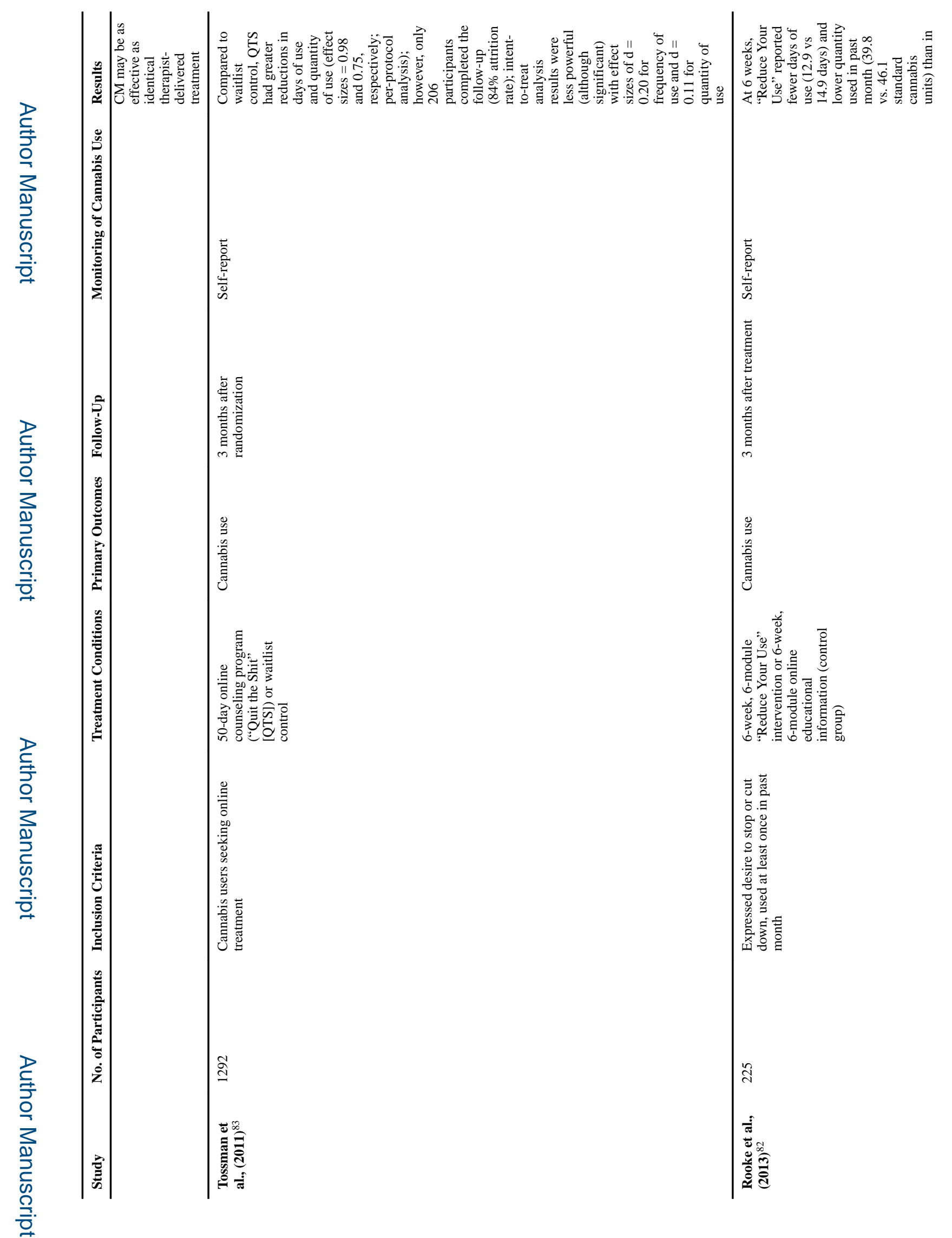




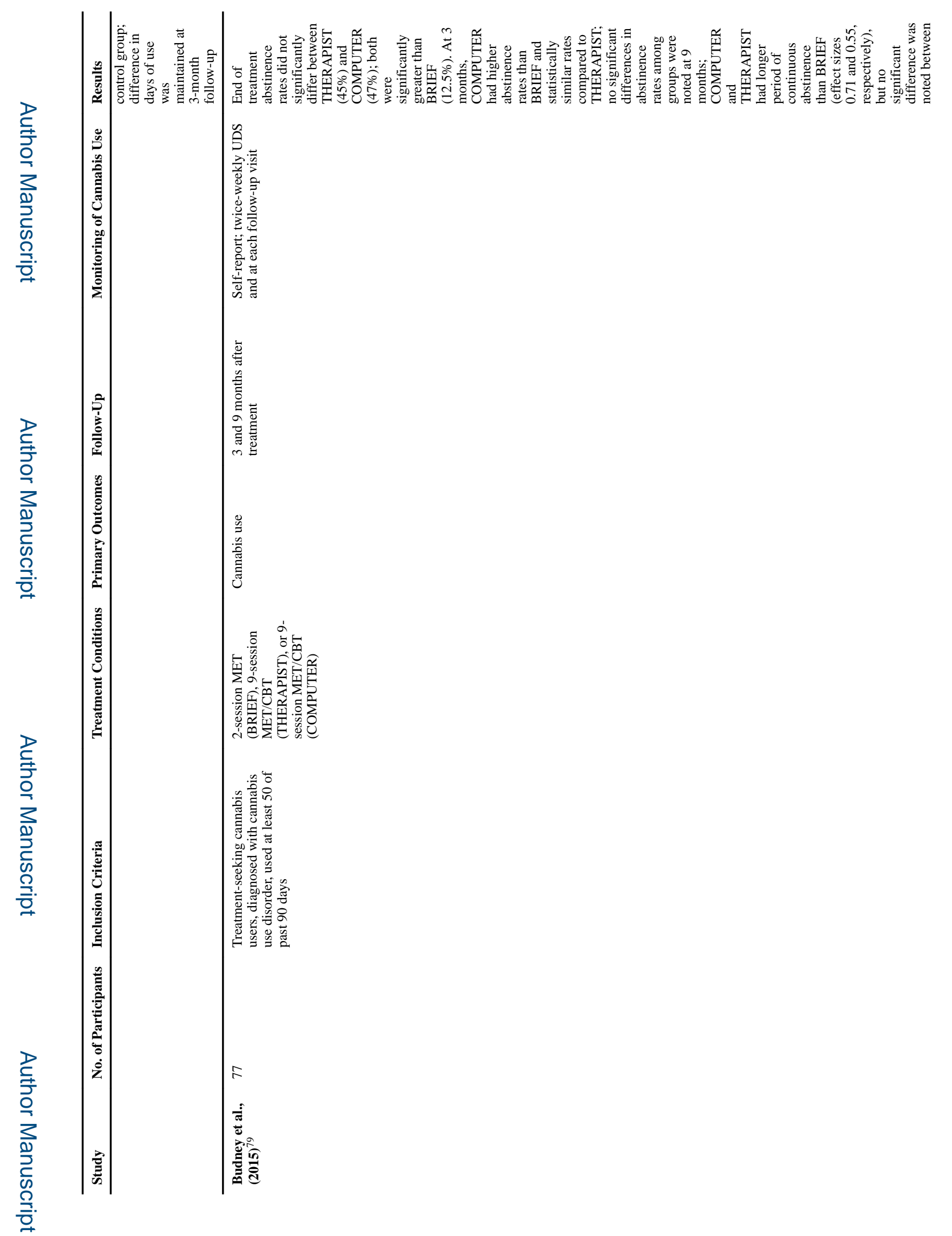




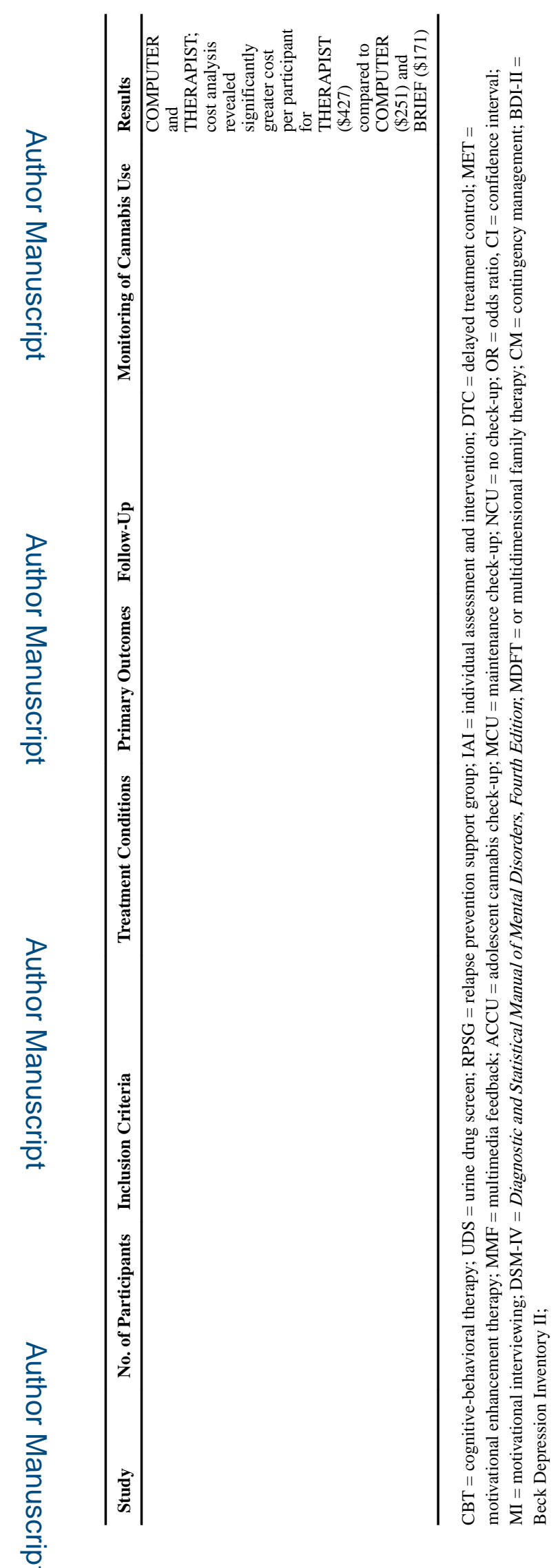

Pharmacotherapy. Author manuscript; available in PMC 2017 May 01. 


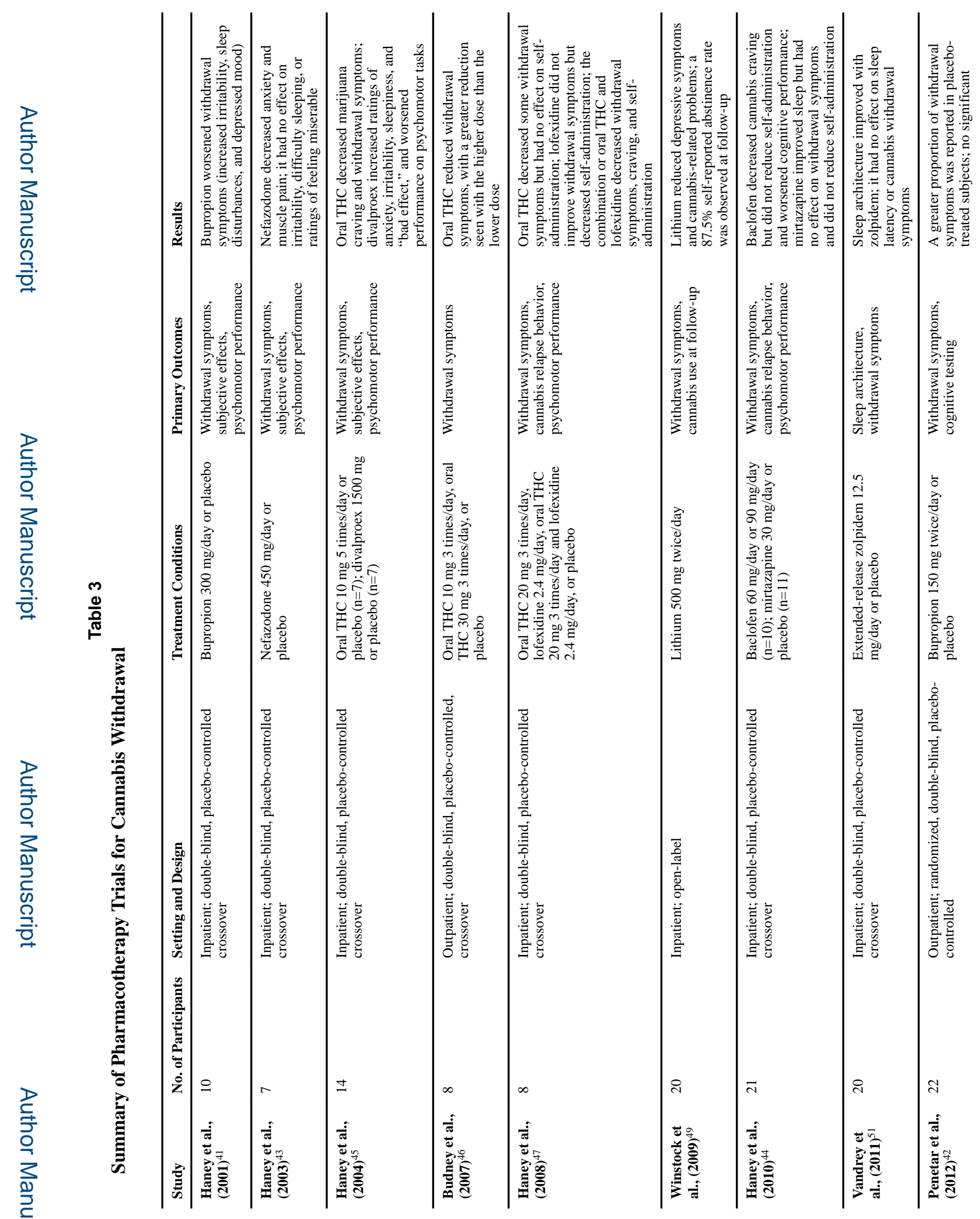

Pharmacotherapy. Author manuscript; available in PMC 2017 May 01. 


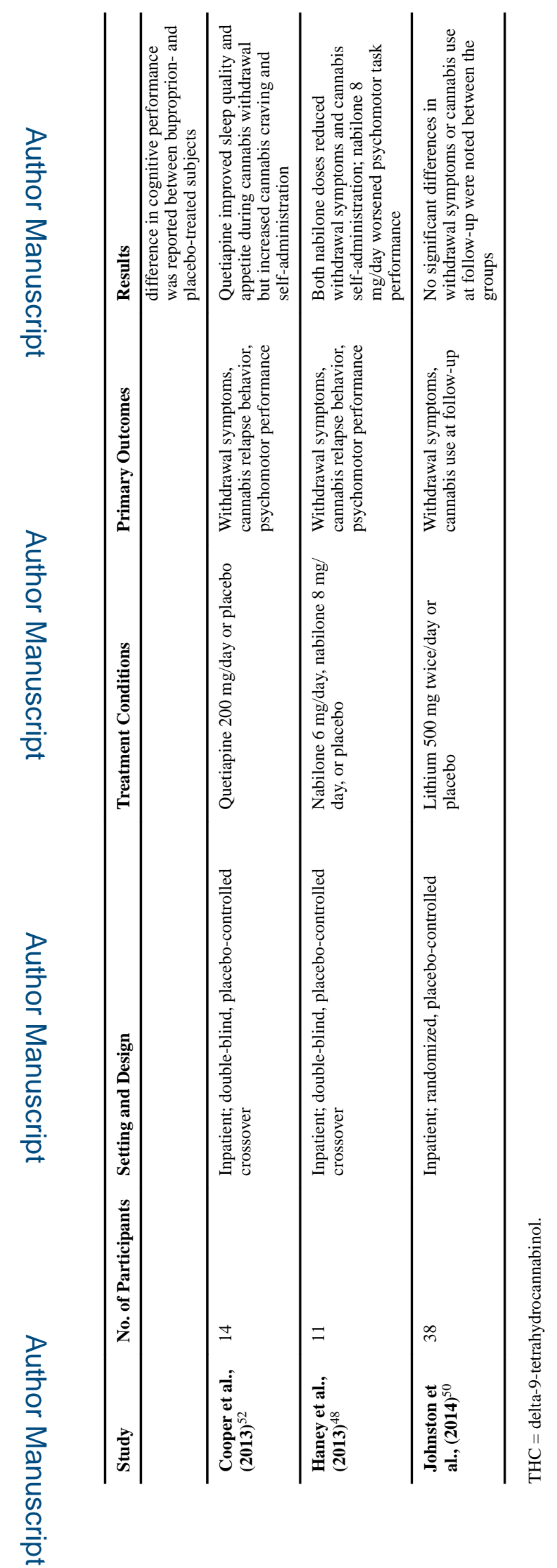

Pharmacotherapy. Author manuscript; available in PMC 2017 May 01. 


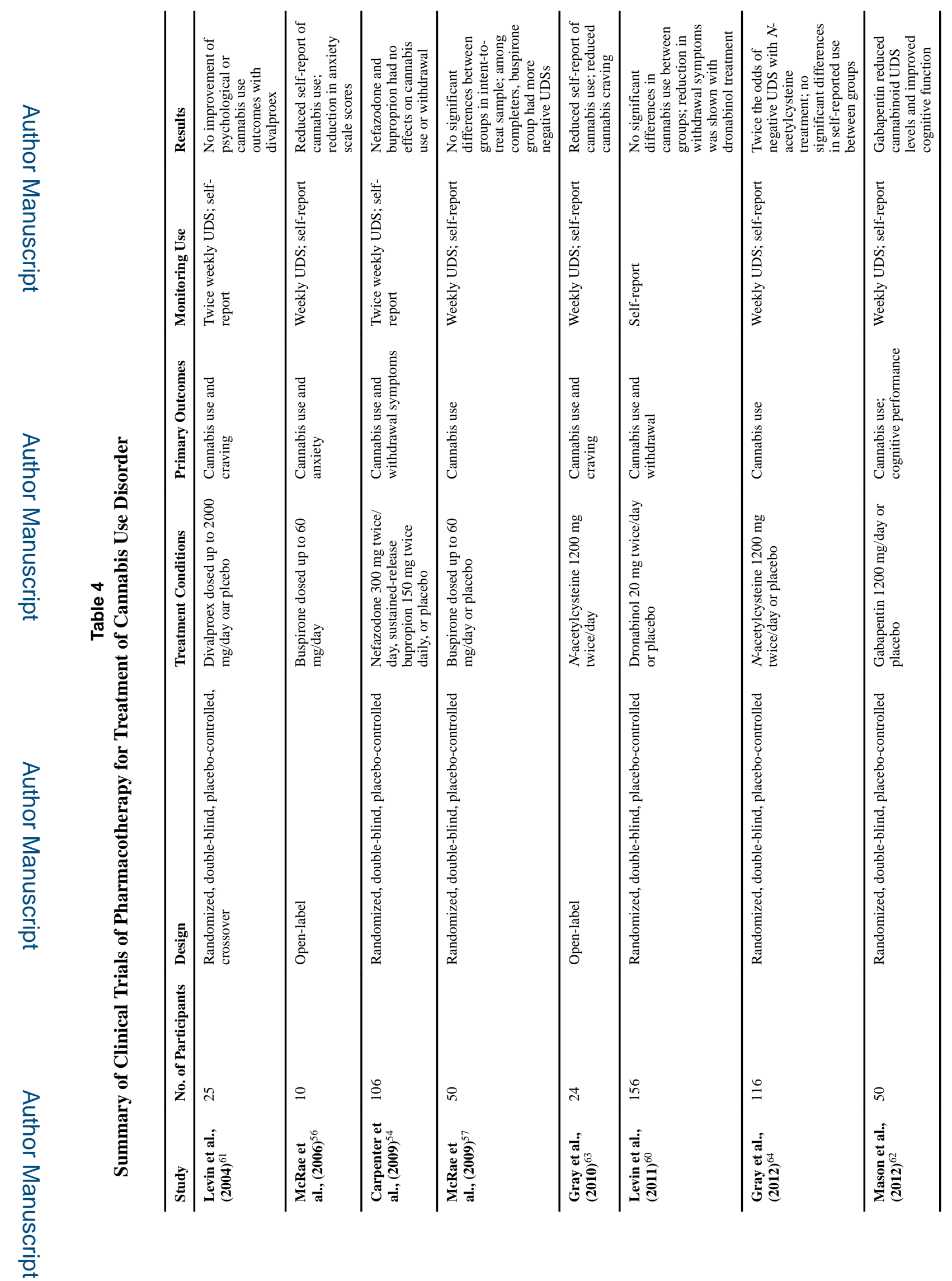

Pharmacotherapy. Author manuscript; available in PMC 2017 May 01. 


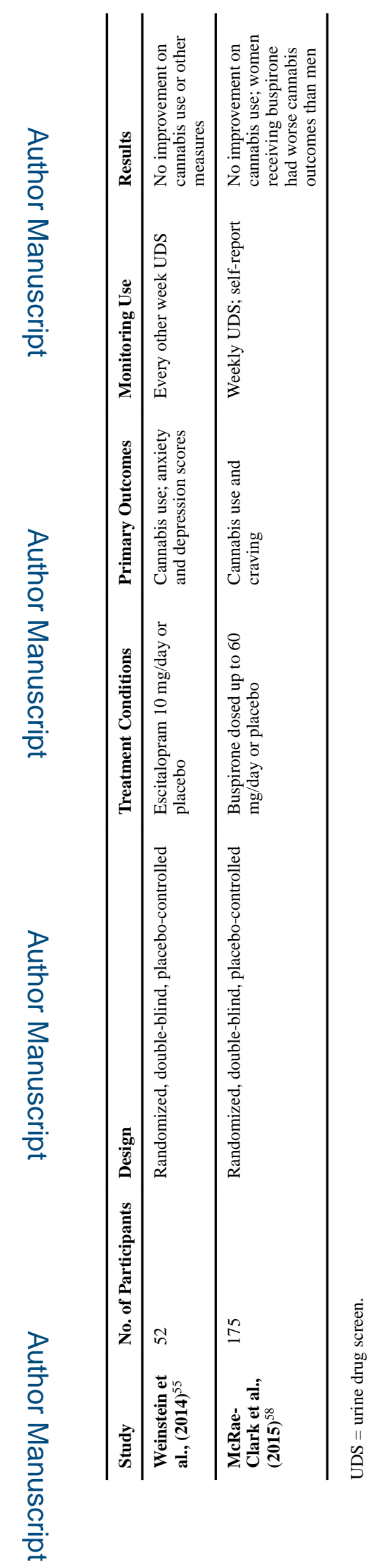

Pharmacotherapy. Author manuscript; available in PMC 2017 May 01. 